This is a peer-reviewed, accepted author manuscript of the following research chapter: Mulvey, R. E., \& Robertson, S. D. (2013). Modern developments in magnesium reagent chemistry for synthesis. In S. Harder (Ed.), Alkaline-Earth Metal Compounds: Oddities and Applications (pp. 103-140). (Topics in Organometallic Chemistry; Vol. 45). Springer. https://doi.org/10.1007/978-3-642-36270-5

\title{
Modern Developments in Magnesium Reagent Chemistry for Synthesis
}

\author{
Robert E. Mulvey and Stuart D. Robertson
}

\begin{abstract}
This year (2012) commemorates the $100^{\text {th }}$ anniversary of the award of the Nobel Prize to Victor Grignard for his development of Grignard reagents (at the simplest level expressed as " $\mathrm{RMgX}$ " where $\mathrm{R}$ is an organic group and $\mathrm{X}$ is a halogen), one of the most widely utilized classes of synthetic reagent. A century on but only in the past decade or so has magnesium reagent chemistry entered a new and exciting phase, surpassing the limitations of what traditional Grignard reagents can do. Modern magnesium reagents have been designed to possess essentially comparable reactivity to their great rivals, organolithium reagents (traditional Grignard reagents are orders of magnitude less reactive than organolithium reagents) but at the same time to maintain the superior selectivity and broader functional group tolerance of their traditional ancestors. The key to the design of these new reagents is their multi-component constitution with the organomagnesium engine powered by an activating alkali metal additive, often a halide salt or another organometallic entity. This chapter outlines some of the most significant advances in this emerging field.
\end{abstract}

Keywords Alkali-metal · Deprotonation · Magnesiate · Synthesis · TurboGrignard Reagents

\section{Contents}

1 History: a brief glimpse

2 Modern Advances Part One - The Halide Salt Method

2.1 Introduction

2.2 Uses in Metal-Halogen Exchange Reactions

2.3 Uses in Metal-Hydrogen Exchange Reactions

3 Modern Advances Part Two - The Organic Anion Approach

3.1 Introduction

3.2 Uses in Metal-Halogen Exchange Reactions

3.3 Polymerization 
3.4 Magnesiates as Nucleophile Sources

3.5 Uses in Metal-Hydrogen Exchange Reactions

3.6 Contrasting Reactivity of Higher-Order and Lower-Order Alkyl Magnesiates

3.7 Synthetic Applications using Magnesium Zincates

3.8 Heteroleptic Alkyl/Amido Alkali-Metal Magnesiates

4 Conclusion

References

R.E. Mulvey ${ }^{*}$ and S.D. Robertson

WestCHEM, Department of Pure and Applied Chemistry, University of Strathclyde, Glasgow, UK, G1 1XL.

e-mail: r.e.mulvey@strath.ac.uk 


\section{History: A Brief Glimpse}

The use of magnesium reagents in organic synthetic chemistry can trace its roots back over 100 years thanks to the pioneering work of Victor Grignard [1]. His eponymous centurion reagents [2], the development of which won this French chemist the Nobel Prize for Chemistry in 1912, have been used the world over for organic transformations. Grignard reagents are organomagnesium halides (at the simplest level of formula " $\mathrm{RMgX}$ ") and are generally prepared by the insertion of magnesium metal into a polarised carbon-halogen bond as depicted in Figure 1. They can consequently be used in nucleophilic addition reactions across unsaturated bonds, e.g. a carbonyl functionality, making them highly important reagents for controlled carbon-carbon bond formation.

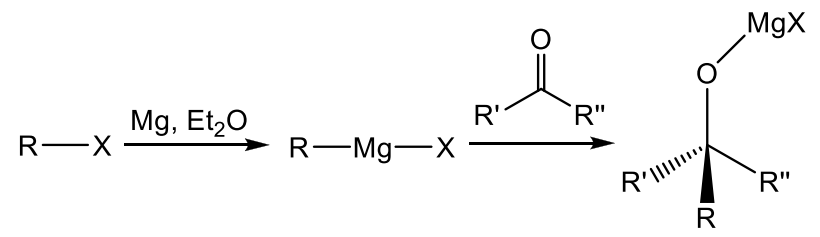

Figure 1. Empirical preparation of a Grignard reagent and its addition across a carbonyl group.

Deprotonative metallation, the breaking of a C-H (or X-H) bond for the making of a more reactive and more synthetically useful C-M (or X-M; where $\mathrm{X}=$ e.g. N, O, $\mathrm{S})$ bond is typically the domain of hard alkali-metal reagents such as alkyl lithiums (R-Li) or lithium secondary amides $\left(\mathrm{R}_{2} \mathrm{~N}-\mathrm{Li}\right)$ which have very polar, reactive metal-ligand bonds, moving towards but not quite reaching $\mathrm{R}^{-}$carbanions or $\mathrm{R}_{2} \mathrm{~N}^{-}$ anions. Indeed, while Grignard's name is synonymous with organomagnesium chemistry, organolithium compounds could arguably be described as "Schlenk reagents" after their pioneer, the German chemist Wilhelm Schlenk, who, unlike Grignard, lost out on a Nobel Prize because the awarding committee did not believe organolithiums would ever be useful![3] Schlenk's contributions in lithium chemistry have however been posthumously recognized by the Gesellschaft Deutscher Chemiker (GDCh, the German Chemists Association), who co-named a biennial award for excellence in the field of theoretical and practical lithium chemistry after him (the Arfvedson-Schlenk Award; with Johan Arfvedson, the Swedish chemist who discovered the element lithium in 1817). In organomagnesium chemistry, Schlenk is commemorated by the equilibrium reaction that disproportionates heteroleptic $\mathrm{RMgX}$ complexes into their homoleptic $\mathrm{R}_{2} \mathrm{Mg}$ and $\mathrm{MgX}_{2}$ component parts, work which was in fact carried out in conjunction with his son, Wilhelm Jr., as part of his PhD studies [4].

The high reactivity of organolithium reagents can also be considered their Achilles heel since it means they routinely have to be sedated by low temperature, are often indiscriminate with regards to the site at which they metallate and they 
also display considerable intolerance towards certain synthetically important functional groups including ester, carbonyl, nitrile, halide and sulfoxide. However, organomagnesium reagents have more covalent, and hence less reactive, metalligand bonds meaning that they can display far superior functional group tolerance and considerably greater chemoselectivity; consequently they can generally be used at room temperature without fear of significant side reactions.

Early developments in the use of magnesium reagents for deprotonative metallation began in the late 1940's, when Hauser and co-workers made progress replacing the alkyl ligand of a Grignard reagent with a secondary amide, with the resultant products $\left[\left(\mathrm{R}_{2} \mathrm{~N}\right) \mathrm{MgX}\right.$ and $\left(\mathrm{R}_{2} \mathrm{~N}\right)_{2} \mathrm{Mg}$; the Hauser bases - although it should be noted that halomagnesium secondary amides were first mentioned as early as 1903 by Meunier [5], around the same time that Grignard was carrying out his own important magnesium studies] finding use in the self condensation of esters [6-7] and in 1,2 or 1,4 nucleophilic additions to derivatives of cinnamic acid (Figure 2) [8].

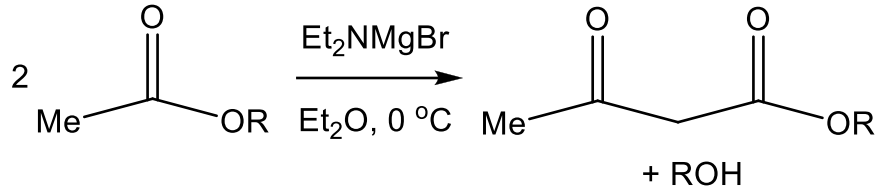<smiles>CCNC(=O)/C=C/c1ccccc1</smiles>

Figure 2. Early reactions of Hauser using a secondary amido magnesium bromide reagent.

Research in this area advanced further in the 1980's and 90's thanks largely to the innovation of Eaton and co-workers, of introducing the sterically demanding secondary amide 2,2,6,6-tetramethylpiperidide (TMP, by then a well known amide in lithium chemistry thanks largely to the work of Olofson [9] and Lappert [10], see Figure 3 for its steric profile) into magnesium chemistry in the form of (TMP)MgBr which was shown to ortho-magnesiate carboxamides (Figure 4) [11].
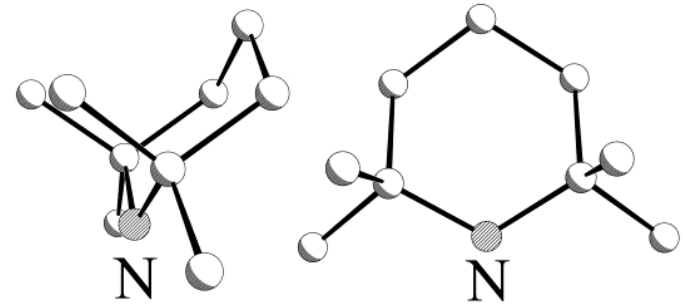

Figure 3. Chair-form of the TMP anion (nitrogen atom shaded) emphasising the considerable steric protection of the anionic nitrogen centre by the methyl arms. 
Mulzer then took this a step further, testing the chloro congener (TMP) $\mathrm{MgCl}$ and discovering that it was more effective than Eaton's reagent for the orthomagnesiation of carbamates and pyridinecarboxamides (Figure 4) [12]. Kondo, Sakamoto and co-workers then re-visited the diisopropylamido magnesium bases $i \operatorname{Pr}_{2} \mathrm{NMgX}(\mathrm{X}=\mathrm{Cl}, \mathrm{Br})$ and $\left(i \operatorname{Pr}_{2} \mathrm{~N}\right)_{2} \mathrm{Mg}$, reporting their utility as selective deprotonating agents for phenylsulfonyl substituted indoles (deprotonating exclusively at the 2-position) [13] and for heterocyclic thiophene and thiazole (again deprotonating exclusively at the 2-position) [14]. Thiazoles with substituents in 2- and 3positions were also examined, with the 5-position being metallated. These reactions were carried out at room temperature in THF, with a 2-fold excess of base required; no di-metallation was ever witnessed despite this excess.

Compared to LiTMP, the bis-amido reagent (TMP) ${ }_{2} \mathrm{Mg}$ finds extremely limited use in synthetic transformations as it is a kinetically poor base. (TMP) ${ }_{2} \mathrm{Mg}$ does however have one considerable advantage, it is stable in refluxing THF and consequently can be utilized with poorly soluble/unreactive substrates. This reagent also displays tolerance of ester functionality as demonstrated by Eaton who orthomagnesiated methyl benzoate at room temperature in less than one hour [11]. Mulvey and co-workers deprotonated a methyl arm of lithium 1,1,1,3,3,3hexamethyldisilazide (LiHMDS) with $(\mathrm{TMP})_{2} \mathrm{Mg}$, resulting in a heterometallic, heteroleptic chiral complex of empirical formula $\mathrm{LiMg}(\mathrm{TMP})\left[\mathrm{N}\left(\mathrm{SiMe}_{3}\right)\left(\mathrm{SiMe}_{2} \mathrm{CH}_{2}\right)\right]$ [15]. Also, in a recent paper by Kawachi et al., a diaminoborylbenzene was intramolecularly ortho-magnesiated with $(\mathrm{TMP})_{2} \mathrm{Mg}$ (Figure 4), with the solid-state structure revealing that the metallated intermediate is co-complexed with another molecule of (TMP) $)_{2} \mathrm{Mg}$ and then dimerizes to give a tetramagnesiate [16], a common motif in magnesium structural chemistry. 

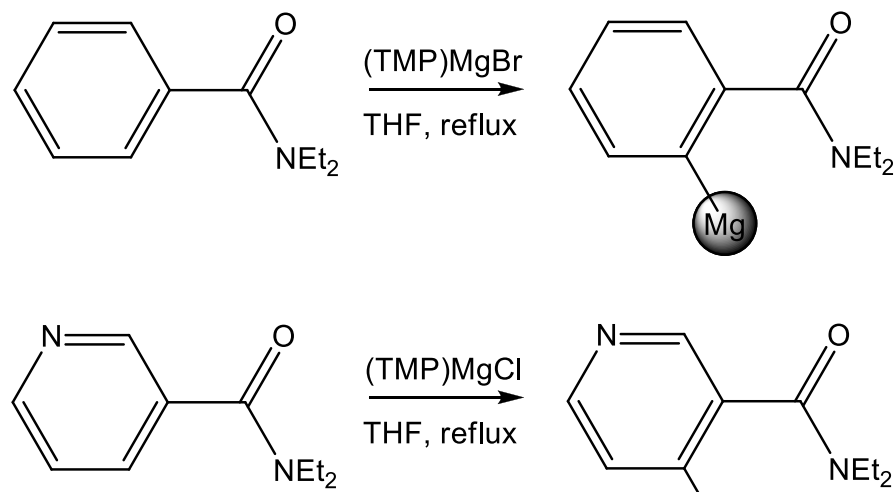

(TMP) $\mathrm{MgCl}$

THF, reflux

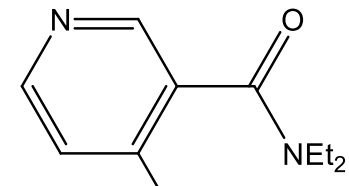

Mg

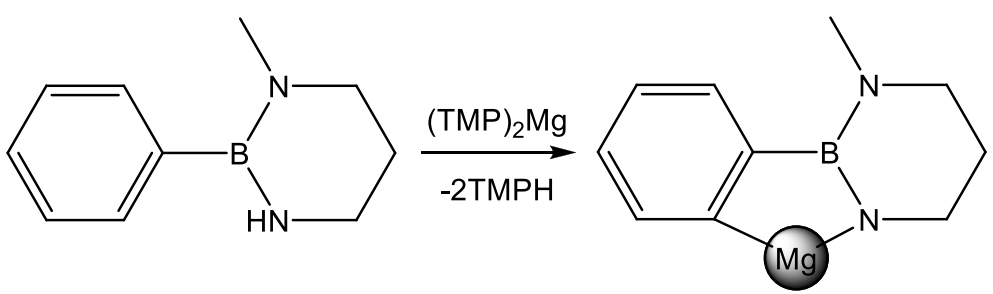

Figure 4. Examples of TMP-magnesium reagents being used in selective deprotonation reactions.

A driving force for reactions such as these, whether by lithium or in a considerably more limited way by magnesium reagents, is the presence of an orthodirecting group - typically a functional group containing a Lewis basic heteroatom sometimes within a double or triple bond. In a protocol elaborated by Snieckus and Beak and known as directed ortho metallation (DoM) [17], the functional group plays a dual role in promoting the metallation reaction. This is achieved firstly through the complex induced proximity effect (CIPE), whereby the heteroatom's lone pair of electrons can act as an anchor point for the Lewis acidic metal reagent, holding it in place close to the ortho site to allow it to execute the deprotonation (Figure 5). The second influence is through an inductive acidifying effect, whereby the electron withdrawing nature of the substituent increases the acidity of the nearest (ortho) hydrogen atom and has a stabilizing influence over the resulting carbanion. 


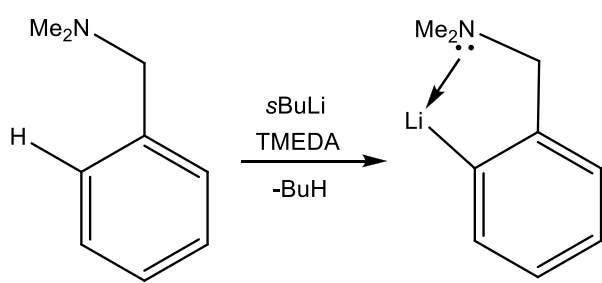

Figure 5. A representative example of Directed ortho Metallation.

Magnesium reagents, which have less polar metal-anion bonds making them less reactive are generally much less suited to deprotonating aromatic substrates. Furthermore, they can be poorly soluble in organic solvents, meaning that a large excess of base is required. The knock-on effect of this is that competing reactions between the excess base and any electrophile can complicate functionalization of the metallated intermediate. Further complications involve bisamido magnesium reagents acting as reducing agents (i.e. sources of hydride ion from organic frameworks) while the sluggish reactivity of these complexes often requires heating to induce reaction at reasonable rates. These negative points have recently started to be addressed by using a bimetallic (or more strictly a multi component) approach, that is by combining the less reactive (softer) magnesium reagent with a more reactive (harder) alkali-metal reagent, with the resulting heterometallic complex seemingly displaying the beneficial properties of each of the component parts (alkali metal reactivity; magnesium selectivity). There are currently two different general approaches by which this can be achieved, either by incorporating the alkali-metal into the molecular framework via a halide salt or alternatively via an organometallic reagent. These two distinct approaches are summarized in the following section.

\section{Modern Advances Part One - The Halide Salt Method}

\subsection{Introduction}

The first approach to modifying the reactivity of a magnesium reagent is through the addition of a stoichiometric amount of an alkali-metal halide salt. Lithium chloride $(\mathrm{LiCl})$ appears often ideal for this role. Understanding the role and broad scope of application of $\mathrm{LiCl}$ "additives" in various aspects of s-block metal chemistry is undergoing somewhat of a renaissance recently with for example Collum demonstrating that addition of as little as $0.5 \mathrm{~mol} \% \mathrm{LiCl}$ can have a massive effect 
on reactivity in diverse reactions such as ortho lithiation of arenes directed by halogen containing directing groups [18] or nucleophilic addition of lithium diisopropylamide to unsaturated esters [19]. Within the context of alkaline earth metal chemistry, at the most basic level the halide salt promotes solubility of the parent sterically hindered Hauser base in part due to decreasing aggregation, with the resultant heterometallic co-complex being utilized in polar THF solution. The best documented examples of such "Turbo-Hauser bases", so called because of their increased reactivity with respect to the $\mathrm{LiCl}$ free Hauser base, are the TMP containing bases (TMP) $\mathrm{MgCl} \cdot \mathrm{LiCl}$ (Turbo-A) and (TMP) ${ }_{2} \mathrm{Mg} \cdot 2 \mathrm{LiCl}$ (Turbo-B). These "Turbo-Hauser" reagents, and the less sterically hindered congener $\left(i \mathrm{Pr}_{2} \mathrm{~N}\right) \mathrm{MgCl} \cdot \mathrm{LiCl}$ (Turbo-C), find use as selective metal-hydrogen exchange reagents and were originally designed as a follow up to the "Turbo-Grignard reagent" $i \mathrm{PrMgCl} \cdot \mathrm{LiCl}$ (Turbo-D), which itself was initially prepared as a metal-halogen exchange reagent. Their synthesis is relatively facile; reagents Turbo-A and Turbo-B are prepared by treating reagent Turbo-D with $\mathrm{R}_{2} \mathrm{~N}(\mathrm{H})$ in THF for 24 hours at room temperature, while reagent Turbo-B is simply prepared from Turbo-A and LiTMP. Turbo-D is initially prepared by reaction of metallic $\mathrm{Mg}$ with $i \mathrm{PrCl}$ in the presence of anhydrous $\mathrm{LiCl}$ (see Figure 6 for full details).

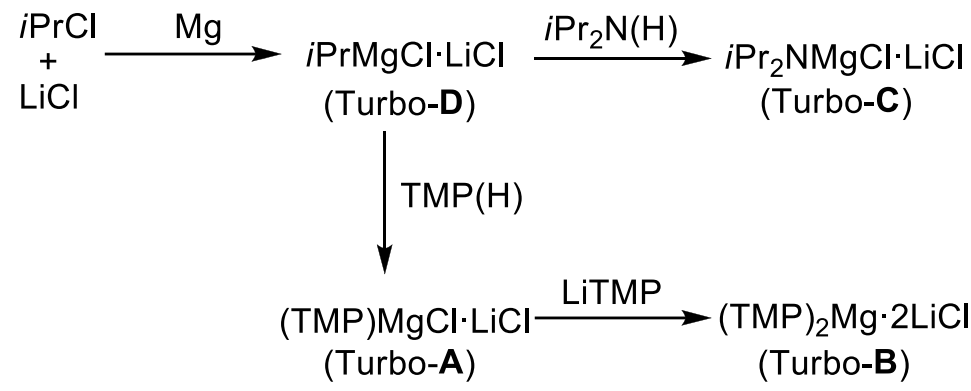

Figure 6. Synthetic protocols for forming Turbo-Grignard (D) and Turbo-Hauser reagents (A, B and $\mathbf{C}$ ).

\subsection{Uses in Metal-Halogen Exchange Reactions}

While $\mathrm{Br} / \mathrm{Li}$ exchange is a relatively fast process and consequently needs to be carried out at low temperature, $\mathrm{Br} / \mathrm{Mg}$ exchange is much slower, meaning heat must be applied which can induce competing side reactions with sensitive functional groups. Thus the use of Turbo-Grignard reagents in metal-bromine exchange reactions perfectly demonstrates the cooperative effects of having two different metals in one reagent, since they can be used successfully under a room temperature regime. Knochel first demonstrated this in the reaction of 4- 
bromoanisole with $i \mathrm{PrMgCl} \cdot \mathrm{LiX}$ (where $\mathrm{X}=\mathrm{Cl}, \mathrm{Br}, \mathrm{BF}_{4}, \mathrm{ClO}_{4}$ ), also proving that $\mathrm{LiCl}$ is superior to other alkali-metal salt additives through systematically varying the salt component $\mathrm{LiX}$ [20]. The $\mathrm{LiCl}$ additive also modifies the selectivity, since $i \mathrm{PrMgCl}$ will react with a para-iodo dioxaborolane at the boronic ester functionality yet $i \mathrm{PrMgCl} \cdot \mathrm{LiCl}$ will execute direct magnesiation via $\mathrm{Mg} / \mathrm{I}$ exchange (Figure 7) $[21]$

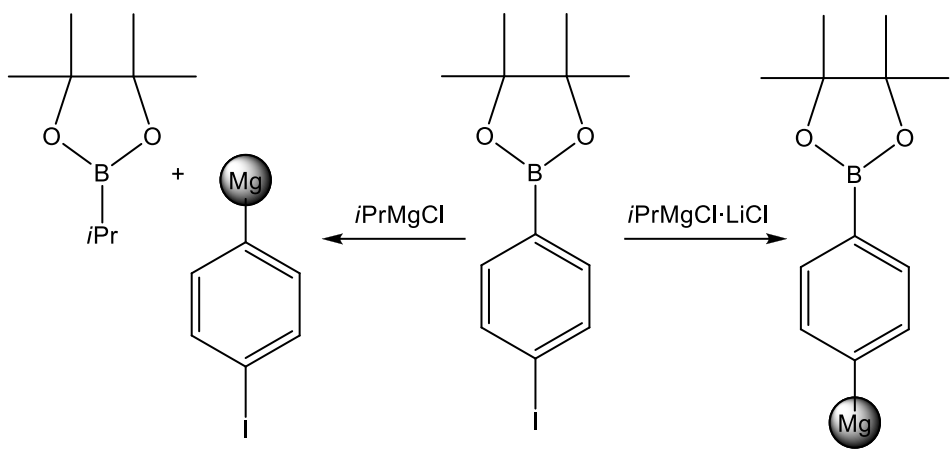

Figure 7. Contrasting reactivity of $i \mathrm{PrMgCl}$ in the absence and presence of $\mathrm{LiCl}$.

It is not only aromatic carbon-halogen bonds which are susceptible to metallation with a Turbo-Grignard reagent under mild conditions but also alkenyl ( $s p^{2}$ hybridised) carbon-halogen bonds. For example, as shown in Figure 8, Knochel has extended the use of the reagent $i \mathrm{PrMgCl} \cdot \mathrm{LiCl}$ to the functionalization of cyclic and acyclic alkenyl iodides such as 1-iodo-3-methylenecyclohex-1-ene and 1-iodo-oct1 -ene with retention of stereochemistry upon electrophilic quenching; importantly additional studies on related substrates showed that nitrile, halide and ester functionalities are all tolerated during this metallation (soft magnesiation) [22-23].

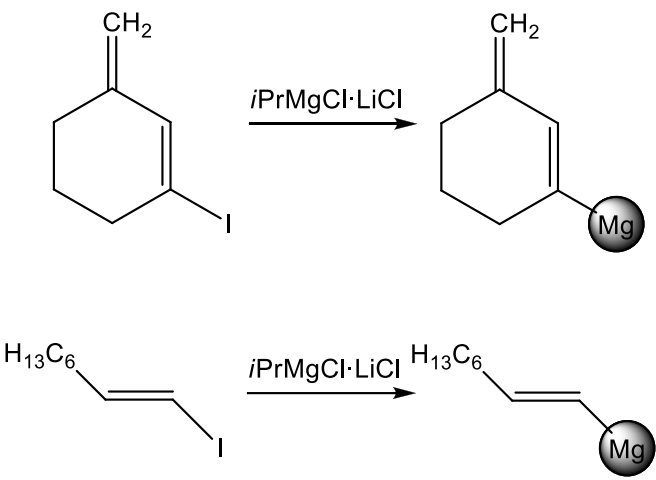

Figure 8. Examples of metal-halogen exchange of olefinic substrates using Turbo-D. 


\subsection{Uses in Metal-Hydrogen Exchange Reactions}

While the 'Turbo-Grignard' reagents are proficient at metal-halogen exchange, the amide based 'Turbo-Hauser' reagents are more useful in selective metal-hydrogen exchange, i.e. deprotonation reactions. Diisopropylamido reagent Turbo-C was discovered to be less reactive than its TMP counterparts Turbo-A or Turbo-B for deprotonative metallation reactions due at least in part to its lower solubility. This reactivity difference was established by the deprotonation of isoquinoline: only two hours at room temperature are required with 1.1 molar equivalents of reagent A; while 12 hours and two molar equivalents of reagent $\mathbf{C}$ are needed for comparable (>90\%) metallation efficiency (Figure 9) [24].<smiles>CC(C)c1ccc2ccccc2c1</smiles>

Figure 9. Contrasting reactivity of Turbo-A and Turbo-C for direct magnesiation of isoquinoline.

This difference in solubility and reactivity can be attributed at least in part to differing aggregation states, proven by the elucidation of solid state structures (Figure 10) which show Turbo-A to exist in a dinuclear arrangement [25] while Turbo-C adopts a dimeric, tetranuclear motif [26]. A Diffusion Ordered SpectroscopY (DOSY) NMR study revealed however that these molecular constitutions are not retained in the solution state, with the presence of solvent separated ion-pairs (ates - believed to be $\left[\mathrm{Li}(\mathrm{THF})_{4}\right]^{+}\left[\mathrm{RMgCl}_{2} \cdot(\mathrm{THF})_{\mathrm{x}}\right]^{-}$) seemingly being responsible for the observed reactivity.

Of course other factors are also partly responsible for this differing reactivity, most obviously the steric and electronic make-up of the active base as TMP is a more reactive base than diisopropylamide with the $\mathrm{p} K_{\mathrm{a}}$ of $\mathrm{TMP}(\mathrm{H})$ (37.3) being greater than that of DA(H) (35.7) [27]. However, it should be stressed that caution must be applied when considering $\mathrm{p} K_{\mathrm{a}}$ values of metal bases as the final value is a function of not only the metal in question, but also of solvent, concentration and temperature. 

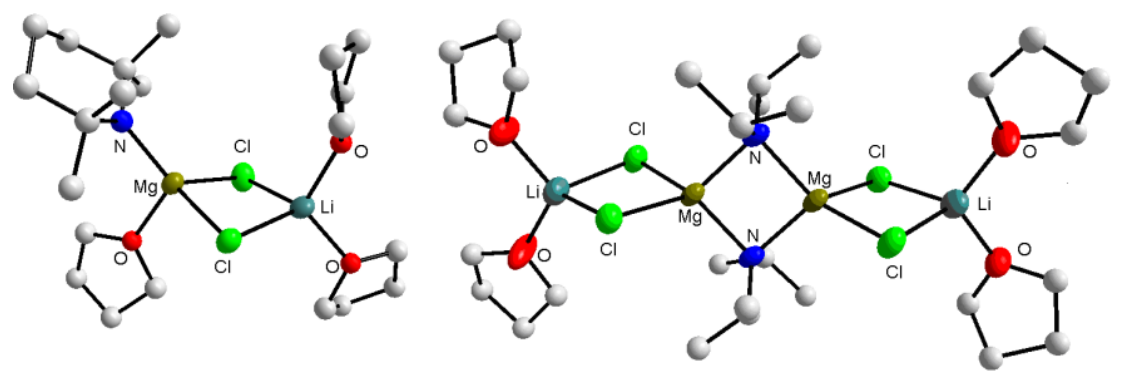

Figure 10. Molecular structures of Turbo-A and Turbo-C with $\mathrm{H}$ atoms omitted for clarity.

The principal advantages of the bases described thus far are their high kinetic basicity, coupled with good solubility, high chemoselectivity and improved functional group compatibility compared to homometallic organo alkali metal or magnesium bases. Routinely they are utilized in the temperature range of $-20{ }^{\circ} \mathrm{C}$ to 25 ${ }^{\circ} \mathrm{C}$ which is a particularly desirable feature for the synthetic chemist and for the process chemist. Selectivity and room temperature compatibility are clearly illustrated by the example of the sensitive ether-functionalized heterocycle 2,4dimethoxypyrimidine which is metallated preferentially at the 5-position by LiTMP in diethyl ether at $0{ }^{\circ} \mathrm{C}$ [28] but at the 6-position by Turbo-A at room temperature in THF solution [29] (Figure 11).

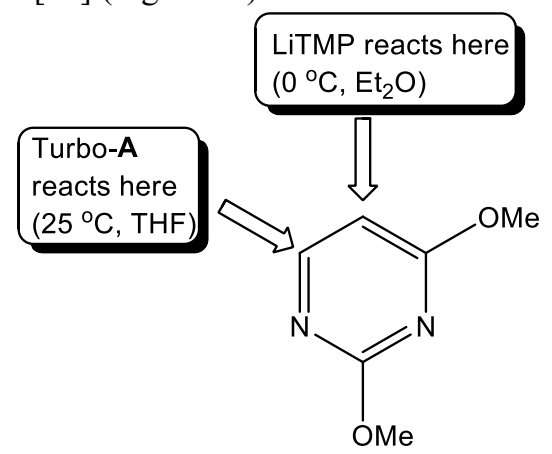

Figure 11. Contrasting sites of metallation using a homometallic or heterometallic reagent.

The applicability of Turbo-Hauser A towards aromatic substrates is expertly proven by the susceptibility of the substituted aromatic ethyl 3-chlorobenzoate to undergo four consecutive direct magnesiations/electrophilic quenches to yield a hexa-substituted benzene derivative (Figure 12) [30]. The second metallation requires careful choice of solvent; in neat THF a competitive deprotonation occurs in a 90:10 ratio in favour of the desired product, which can be improved to a near quantitative level of 98.5:1.5 ratio by employing the less polar $\mathrm{THF} / \mathrm{Et}_{2} \mathrm{O}$ (1:2) 
mixture. It should also be noted that the third and fourth metallations must be carried out at $-50{ }^{\circ} \mathrm{C}$, reflecting the greater sensitivity of the multi-functionalized benzenes.<smiles>CCOC(=O)c1c(C#N)c(Cl)c(C2CCCC2)c(-c2ccccc2)c1C(=O)OCC</smiles>

Figure 12. Reaction sequence using Turbo-A multiple times to give a hexasubstituted benzene.

In the absence of electron donating functionality on the heteroatomic ring, electron deficient pyridine rings are generally challenging to metallate with conventional lithium containing reagents. However this challenge can be met by employing Turbo-A in THF solution resulting in the formation of functionalized pyridines in high yield. Non-activated pyridines can also be metallated by a slightly modified derivative of Turbo- $\mathbf{A}$, whereby Lewis acidic $\mathrm{BF}_{3}$ is incorporated into the base to generate the Lewis acid-Lewis base multicomponent complex $\mathrm{TMPMgCl} \cdot \mathrm{BF}_{3} \cdot \mathrm{LiCl}\left(\mathbf{A} \cdot \mathrm{BF}_{3}\right)$ [31]. The presence of the Lewis acidic $\mathrm{BF}_{3}$ clearly plays an important role through pre-complexation to the substrate as demonstrated by the reaction of heterocyclic 3-fluoropyridine. This substrate is metallated at the 2 position with Turbo-A on its own, however in the additional presence of $\mathrm{BF}_{3}$ direct magnesiation switches exclusively to the more remote 4-position (Figure 13). 


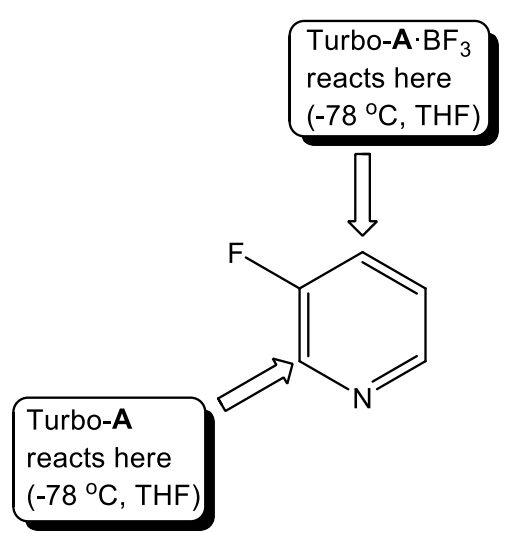

Figure 13. Contrasting reactivity of Turbo- $\mathbf{A}$ in the presence and absence of $\mathrm{BF}_{3}$.

Other important direct magnesiations of aromatic substrates with Turbo-Hauser $\mathbf{A}$ carried out by Knochel and co-workers include key steps in the preparation of the NK3 receptor antagonist 'talnetant' [32] and the fungicide 'mepanipyrim' [33] (Figure 14). Knochel has also expertly applied reagent $\mathbf{A}$ in direct magnesiation reactions of various thiophene containing units, an important subunit within pharmaceuticals, for example by carrying out four consecutive magnesiations to yield a tetrasubstituted derivative [34]. The more complex thienothiophene subunit, which boasts applications in materials chemistry due to its conjugated $\pi$ system, can also be magnesiated directly with Turbo-A, while this protocol can be applied for the preparation of linear oligomeric thienothiophene molecules (Figure 14) [35]. Mori has also recently used Turbo-A as well as the bromo congeners (TMP) $\mathrm{MgBr} \cdot \mathrm{LiBr}$ and $(\mathrm{TMP})_{2} \mathrm{Mg} \cdot 2 \mathrm{LiBr}$ as selective deprotonating agents with substituted thiophenes to efficiently prepare well-defined head-to-tail oligomers [36-37]. 

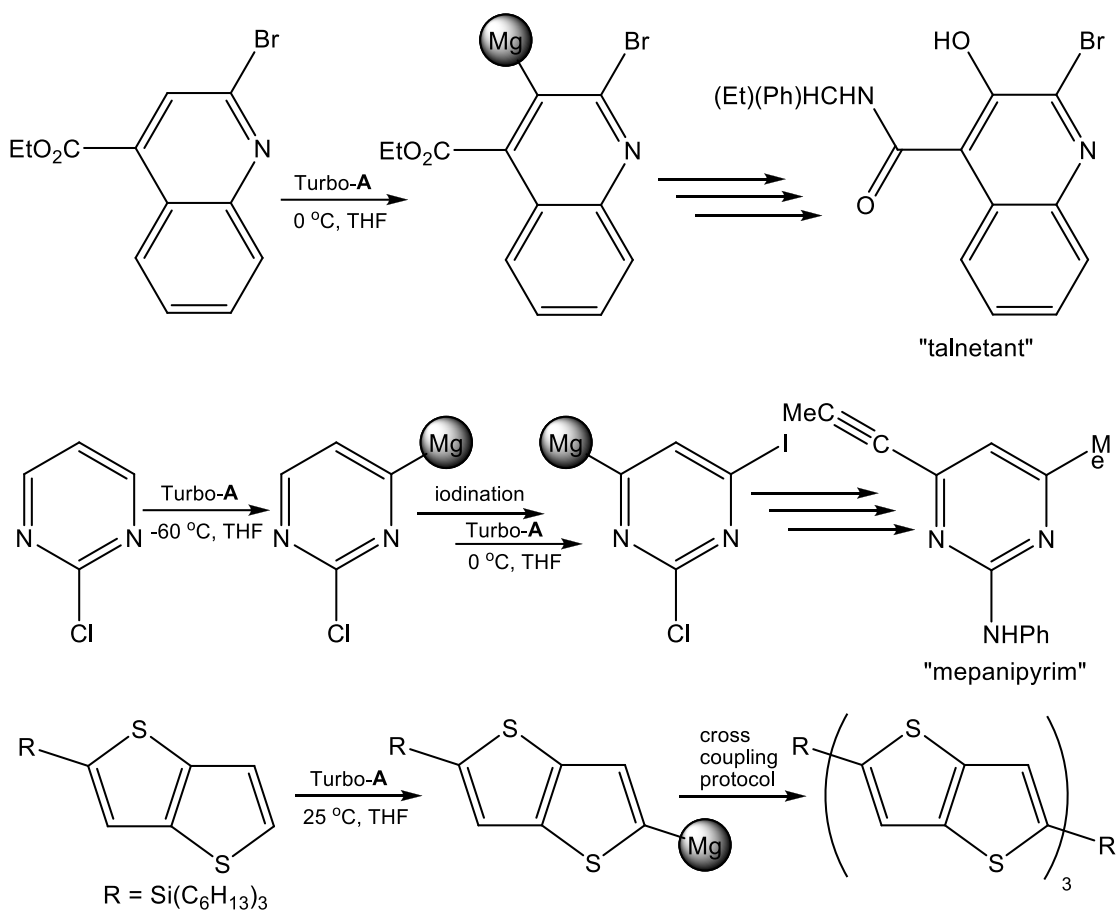

Figure 14. Representative synthetic applications of Turbo-A.

The synthetic utility of reagent $\mathbf{A}$ has also been exploited by Maes and coworkers, who have studied its reaction with pyridazin-3(2H)-ones (Figure 15) [38]. Interestingly $\mathrm{C} 4$ deprotonation was achieved with 5- and 6- halogenated derivatives using Turbo-A; while in contrast nucleophilic addition and magnesiumhalogen exchange (order and mechanism not specified) were witnessed with two molar equivalents of the classical Grignard reagent MesMgBr.

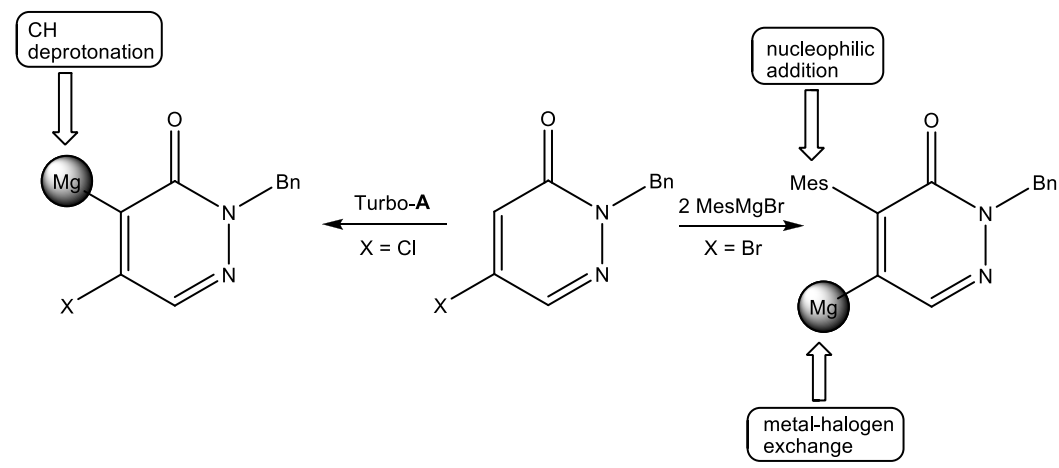

Figure 15. Contrasting reactivity of Turbo-A versus a conventional Grignard reagent. 
The excellent direct magnesiating properties of Turbo-Hauser reagent $\mathbf{A}$ extends beyond the confines of aromatic substrates (though these are by far the most frequently encountered substrates in such transformations). For example, the ether functionalized ester, ethyl 2-ethoxyacrylate can be selectively magnesiated in a reaction favoured by the stabilizing effect of the adjacent carbonyl group, with work up of the reaction mixture affording a non-aromatic cyclic lactone in an excellent yield (Figure 16) [39].<smiles>CCOC(=O)/C=C/C(=O)OCC</smiles>

Figure 16. Direct magnesiation of an olefinic substrate using Turbo-A.

The importance of $\mathrm{LiCl}$ activation is emphasised by Urabe and co-workers, who demonstrated that nucleophilic substitution of a hydride anion by $\mathrm{CH}_{2} \mathrm{Ph}$ in a phenylsilane substrate can be achieved in a considerably greater yield using $\mathrm{PhCH}_{2} \mathrm{MgBr}$ in the presence of a stoichiometric amount of the lithium salt (Figure 17) [40]. Interestingly, the amount of $\mathrm{LiCl}$ could be reduced to only $5 \mathrm{~mol} \%$ without a decrease in conversion when compared to the stiochiometric reaction.<smiles>[R][Si]([2H])([CH])[PbH]</smiles><smiles></smiles><smiles>[R][SiH](C)c1ccccc1</smiles>

$\begin{array}{|ccc|}\underline{\mathrm{R}} & \underline{\mathrm{x}} & \text { vield } \\ \mathrm{Me} & 1 & 77 \\ \mathrm{Me} & 0 & 3 \\ \mathrm{Ph} & 1 & 74 \\ \mathrm{Ph} & 0 & 7\end{array}$

Figure 17. Influence of $\mathrm{LiCl}$ on the silylation of a Grignard reagent.

In cases where a stronger base than Turbo-A is required (generally when the organic substrate has a high $\mathrm{p} K_{\mathrm{a}}$ value), the bis-amido Hauser reagent $(\mathrm{TMP})_{2} \mathrm{Mg} \cdot 2 \mathrm{LiCl}(\mathbf{B})$, equipped with two active base units, can be employed. Its enhanced reactivity (higher kinetic basicity) is demonstrated indirectly by the fact that it is only stable for 24 hours at room temperature in THF solution, while beyond this time a considerable decrease in reactivity is witnessed, at least in part to ring cleavage of THF. The less sterically hindered bis-amido reagent $[(t \mathrm{Bu})(i \mathrm{Pr}) \mathrm{N}]_{2} \mathrm{Mg} \cdot 2 \mathrm{LiCl}$ (Turbo-E) does not suffer from such a reactivity decrease, maintaining its activity after 21 days in THF at $4{ }^{\circ} \mathrm{C}$. Knochel has utilized Turbo-B for direct ortho-magnesiation in the synthesis of 6-hexylsalicylic acid, a component of the essential oil of Pelargonium sidoides DC [41], while Turbo-E will directly magnesiate benzonitrile in THF at $-30{ }^{\circ} \mathrm{C}$ in only 3 hours (Figure 18) [42]. 


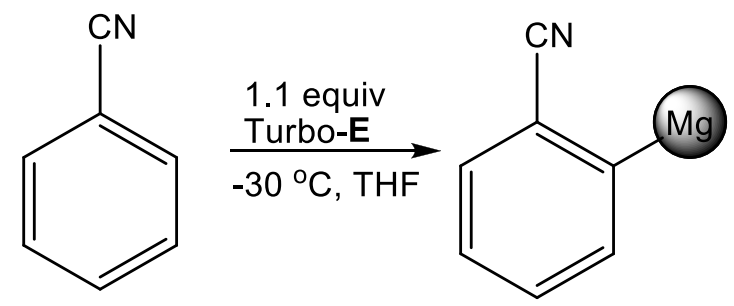

Figure 18. Direct ortho-magnesiation of benzonitrile using Turbo-E.

Like reagent $\mathbf{A}$, Turbo-Hauser $\mathbf{B}$ is an effective magnesiating agent for nonaromatic, olefinic substrates. A lactone, a piperidine [39] and a camphor derivative [43] have all been smoothly magnesiated using Turbo-B in less than 30 minutes in the temperature range $-30{ }^{\circ} \mathrm{C}$ to $+25{ }^{\circ} \mathrm{C}$ with functionalization of the magnesiated intermediate giving the final product in good to excellent yield (Figure 19).<smiles>CCCCCCC(=O)O[Ge]C1C=C(OCC)C(=O)O1</smiles><smiles>CCOC(=O)[GeH2]C1OC(=O)C(OCC)=C1c1ccccc1</smiles><smiles>CCOC1=CN(C)CCC1</smiles><smiles>CCOC(=O)C1=C(c2ccccc2)N(C)CCC1</smiles><smiles>CCOP(=O)(OCC)OC1=CC2CCC1(C)C2(C)C</smiles><smiles>CCOP(=O)(OCC)OC1=C(c2ccccc2)C2(C)CCC1(C)C2(C)C(F)(F)F</smiles>

Figure 19. Direct metallation of olefinic substrates with Turbo-B.

Knochel has recently reported a number of other heterometallic magnesium containing bases such as the heterotrimetallic cocomplexes (TMP) ${ }_{2} \mathrm{Zn} \cdot 2 \mathrm{MgCl}_{2} \cdot 2 \mathrm{LiCl}$, $(\mathrm{TMP})_{2} \mathrm{M} \cdot 2 \mathrm{MgCl}_{2} \cdot 4 \mathrm{LiCl}\left(\mathrm{M}=\mathrm{Mn}\right.$ [44], Fe [45]) and (TMP) $4 \mathrm{Zr} \cdot 4 \mathrm{MgCl}_{2} \cdot 6 \mathrm{LiCl}$ [46]. However, these only incorporate the alkaline earth metal seemingly as a solubilising salt additive in the form of $\mathrm{MgCl}_{2}$ while the metallation appears to be ac- 
tually carried out by the TMP-bound metal and as such these complexes, the structures of which are unknown, fall beyond the scope of the present discussion. We do note here however that $\mathrm{MgCl}_{2}$ has a profound role to play since its absence in for example (TMP) ${ }_{2} \mathrm{Zn} \cdot 2 \mathrm{LiCl}$ greatly reduces the reactivity of the cocomplex [47].

\section{Modern Advances Part Two - The Organic Anion Approach}

\subsection{Introduction}

A second, complementary method for activating magnesium reagents also involves the use of an alkali-metal additive but rather than utilizing this in the form of a halide salt, an organo-alkali metal reagent is preferred. While the application of these complexes has flourished over the past ten or so years, they too can trace their routes back a long time (1951) when another pioneer of magnesium chemistry, Georg Wittig, reported the first lithium magnesiate, " $\mathrm{LiMgPh}_{3}$ " [48]. Incidentally, Wittig succeeded Schlenk as head of organic chemistry at the University of Tübingen. However, unlike his predecessor, Wittig became a Nobel Laureate (1979) albeit not for his contribution to $s$-block chemistry [49]. Wittig coined the name 'ates' to distinguish these complexes from classical organomagnesium and organolithium complexes and noted the reactivity of the central metal (in this case $\mathrm{Mg}$ ) was due to a special 'anionic activation'. In particular, he noted the contrasting reactivity of his ate complex $\mathrm{LiMgPh}_{3}$ against that of its homometallic component $\mathrm{LiPh}$ since the former gives mainly 1, 4 addition to benzalacetophenone while the latter favours 1, 2 addition. The 'ates' descriptor was reinforced by Wittig's student Tochtermann, who published the first review of ate complexes in 1966, 15 years after their initial discovery [50]. Coates and Heslop of the University of Durham were also among the first researchers to note cooperative effects between the different metals in ate formulations [51]. On mixing $n \mathrm{BuLi}$ with $\mathrm{Me}_{2} \mathrm{Mg}$ in solution, they insightfully reasoned that the resulting species "is clearly not simply a mixture of the starting materials, as is evident from the much enhanced solubility of dimethylmagnesium in ether solutions of butyl-lithium". It was also around this time that the development of stoichiometric variant 'higherorder' alkali-metal magnesiates occurred (i.e. alkali-metal rich compounds of general formula $\mathrm{M}_{\mathrm{x}} \mathrm{MgR}_{2+\mathrm{x}}, \mathrm{x}>1$ ). Seitz and co-workers carried out ${ }^{1} \mathrm{H}$ and ${ }^{7} \mathrm{Li} \mathrm{NMR}$ studies to identify the higher-order species present in ethereal mixtures of $\mathrm{MeLi}$ and $\mathrm{Me}_{2} \mathrm{Mg}$ [52] since Hurd had previously identified higher-order complexes in closely related alkali-metal alkyl zincates [53]. Seitz observed at least three different higher order magnesiates in solution in rapid equilibrium, with $\mathrm{x}=2,3$ and 4 . Since these early but crucial observations, structural studies have contributed sig- 
nificantly to a greater understanding of such complexes with both contacted ion and solvent separated derivatives possible. Principal in making such distinctions was Weiss and co-workers, who identified that the contacted ion structures preferred a linear arrangement of metals connected by bridging anions, with tetrahedral strongly Lewis acidic magnesium in the central positions and the alkali-metal occupying the outer region, solvated by a neutral Lewis donor in many cases [54]. Two examples of these so-called Weiss-motifs are depicted in Figure 20.

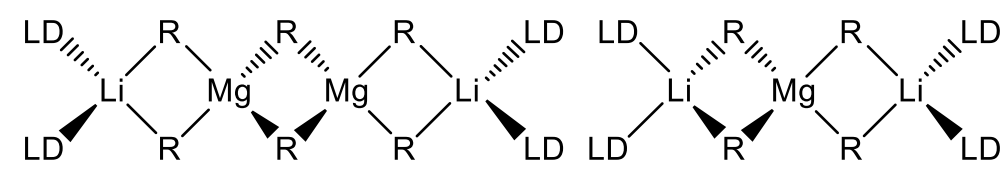

Figure 20. Generic Weiss-motifs of lower-order (left) and higher-order (right) lithium magnesiates $(\mathrm{R}=$ alkyl anion, $\mathrm{LD}=$ neutral Lewis Donor $)$.

It is common though not always the case that higher or lower order variations of magnesiates can be synthesised by simply varying the ratio of organomagnesium to organoalkali-metal reagent in the reaction mixture. Alkali-metal magnesiates can be prepared in various ways. The best known general methods are cocomplexation of the parent diorganomagnesium and organo alkali-metal complexes or salt metathesis of a Grignard reagent/magnesium dihalide with an organo alkali-metal reagent, as shown in Figure 21.

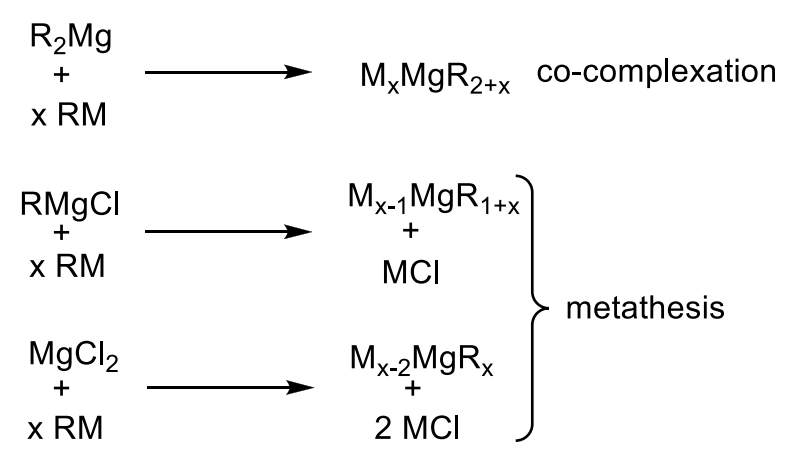

Figure 21. Common preparative routes to alkali-metal magnesiates $(\mathrm{M}=$ alkali-metal).

The former co-complexation method is the most suitable for preparing heteroanionic magnesiates while the latter is more suited to homoanionic magnesiates. By simply varying the stoichiometry of the chosen starting materials, either higher or lower order magnesiates can be obtained. Considering the variation possible in the identity of the organic anions (alkyl, aryl, amido, alkoxy, for example) and any 
neutral Lewis donors it is clear that a vast array of possibilities and permutations exist for alkali-metal magnesiates in general.

\subsection{Uses in Metal-Halogen Exchange Reactions}

As alluded to earlier, lower order magnesiates, where in general the alkali metal to magnesium ratio is unity, have been known since Wittig first described $\mathrm{LiMgPh}_{3}$ in 1951. In the intervening years a number of variations have been described and their utility in synthetic transformations studied in depth. Similar to the heterometallic halide salt magnesiates described in section 2, the alkali-metal alkyl magnesiates can be efficient agents for metal-halogen exchange. Oshima and co-workers have demonstrated this utility in a variety of reactions involving homo- or heteroleptic lithium alkyl magnesiates with halo-substituted aromatics [55]. They found that the ate formed upon mixing $n \mathrm{BuLi}$ with $n \mathrm{Bu}_{2} \mathrm{Mg}$, $\mathrm{LiMg} n \mathrm{Bu}_{3}$, smoothly carries out metal-halogen exchange on aryl halides at $0{ }^{\circ} \mathrm{C}$ in high yield with tolerance of a variety of functionality including ester, amide or cyano groups. They also discovered that the heteroleptic variant $\mathrm{LiMg} i \operatorname{Pr} n \mathrm{Bu}_{2}$ displays greater reactivity than the homoleptic butyl congener since the former could react even at $-78{ }^{\circ} \mathrm{C}$ while the latter could not [56]. Jain and co-workers similarly utilized LiMg $i \operatorname{Pr} n$ $\mathrm{Bu}_{2}$ in metal-halogen exchange of meta and para-halogenated phenols and $\varpi$ phenoxyalcohols with no evidence of ortho-deprotonation occurring [57].

Trisalkyl lithium magnesiates can also be utilized for selective functionalization by carefully tuning the stoichiometry, reactions conditions or identity of the alkyl groups. For example single metal-halogen exchange of homo- or heterodihalogenated aryl substrates is possible (reaction occurring preferentially at the iodo functionality in hetero-dihalogenated examples: see Figure 22a). Double metal-halogen exchange of para-diiodobenzene was accomplished by Oshima and co-workers using one molar equivalent of $\mathrm{LiMg} n \mathrm{Bu}_{3}$; but single metal-halogen exchange could be achieved by using the less reactive bis-methyl modification $\mathrm{LiMg} n \mathrm{BuMe}_{2}$ (Figure 22b). However the tris-butyl reagent $\mathrm{LiMg} n \mathrm{Bu}_{3}$ can only carry out single metal-halogen exchange on para-dibromobenzene (Figure 22c). 
a)<smiles>Brc1ccc(Br)c(CCc2cccc(I)c2)c1</smiles>

b)<smiles>Ic1ccc(-c2ccccc2)cc1</smiles>

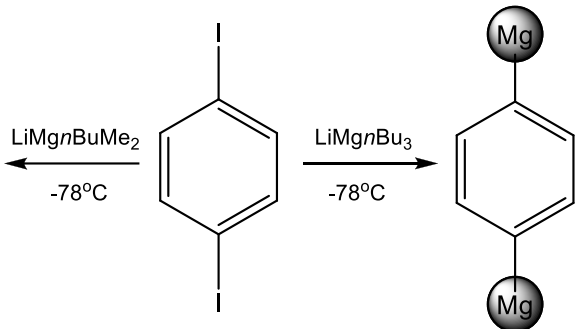

c)<smiles>BrCC(C=Cc1ccc(Br)cc1)CBr</smiles><smiles>CCCCCCCCCCCCCCCCC</smiles>

Figure 22. Selected examples of the use of lithium alkyl magnesiates in metal-halogen exchange reactions with aryl halides.

On moving to ortho-dibromobenzene, single metal-halogen exchange occurs, however the resulting complex with a bromide and metal adjacent to one another is set up to form benzyne via a 1,2 elimination reaction.

Mongin and co-workers have also utilized $\mathrm{LiMgBu}_{3}$ in magnesium-halogen exchange reactions with 2-, 3- and 4-bromoquinoline [58], successfully trapping the magnesiated intermediate with a variety of electrophiles in good yields and also executing the first cross-couplings with lithium triarylmagnesiates to yield polyaromatic heterocyclic organic species [59-60]. Only mild reaction conditions were typically required for such reactions (namely THF or toluene solution, $-10^{\circ} \mathrm{C}, 2-3$ hours).

Iida and Mase have demonstrated the importance of solvent choice in their metal-halogen exchange reactions between $\mathrm{LiMgBu}_{3}$ and 2,6-dibromopyridine [61]. Single magnesium-bromine exchange occurs in both THF and toluene when a 1:1 stoichiometry of metal reagent and substrate are employed. However, when an excess of reagent is utilized in THF solution double metal-halogen exchange 
takes place. Interestingly, on switching to toluene solution only a single exchange reaction occurs even in the presence of excess lithium magnesiate.

Gros and co-workers have recently studied the use of a lithium magnesiate reagent containing a chiral dianionic ligand for enantioselective synthesis[62-63]. In their approach both lower and higher order $\mathrm{LiMgBu}$ (chiral-dianion) and $\mathrm{Li}_{2} \mathrm{MgBu}_{2}$ (chiral-dianion) species execute metal-halogen exchange with 2bromopyridine as the substrate just as efficiently as homoleptic lithium butyl magnesiates. Quenching such magnesiated intermediates with a variety of aldehydes provides a route to chiral alcohols. They also found that $(R, R)$-TADDOL or $(R)$-BIPHEN were the optimum ligands for asymmetric addition (Figure 23). Interestingly the former favours the $R$ enantiomer (optimum enantioselectivity $88: 12$ ) while the latter favours the $S$ enantiomer (17:83). Such optimum enantioselectivity required cryogenic conditions $\left(-100{ }^{\circ} \mathrm{C}\right)$ and resulted in a diminished yield with respect to that obtained on increasing the temperature to $-60{ }^{\circ} \mathrm{C}$. While the enantioselectivity and yields are not ideal, this research represents a promising start for future development in asymmetric synthesis.

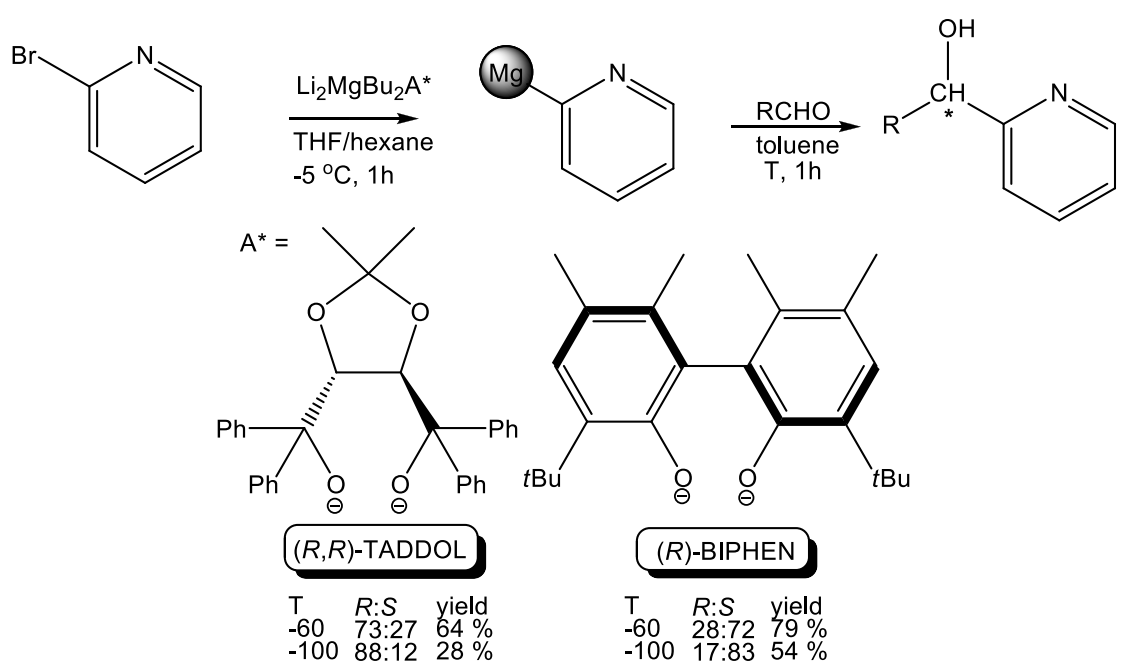

Figure 23. The utilization of chiral dianions in ate formulations for enantioselective synthesis.

Alkali-metal alkyl magnesiates can also be effective for carrying out metalhalogen exchange of aliphatic substrates. An example is provided by Oshima who effected metal-bromine exchange of dibromomethylsilanes with $\mathrm{LiMgBu}_{3}$ at low temperature $\left(-78^{\circ} \mathrm{C}\right)$ in THF (bottom pathway, Figure 24) [64]. Warming the solution to room temperature resulted in (copper catalyzed) alkyl migration with resulting electrophilic quenching yielding $\alpha$-functionalized $\alpha$-silyl pentane. A different reactivity was witnessed for the methyl homologue $\mathrm{LiMgMe}_{3}$, with only the monomethylated bromo product being observed [65]. This distinction was at- 
tributed to the greater reactivity of intermediate $\mathrm{A}$ over $\mathrm{LiMgMe}_{3}$, meaning that $\mathrm{A}$ preferentially abstracts a bromine atom from $\mathrm{R}_{3} \mathrm{SiCHBr}_{2}$ to generate the monomethylated product as demonstrated in the top pathway of Figure 24.

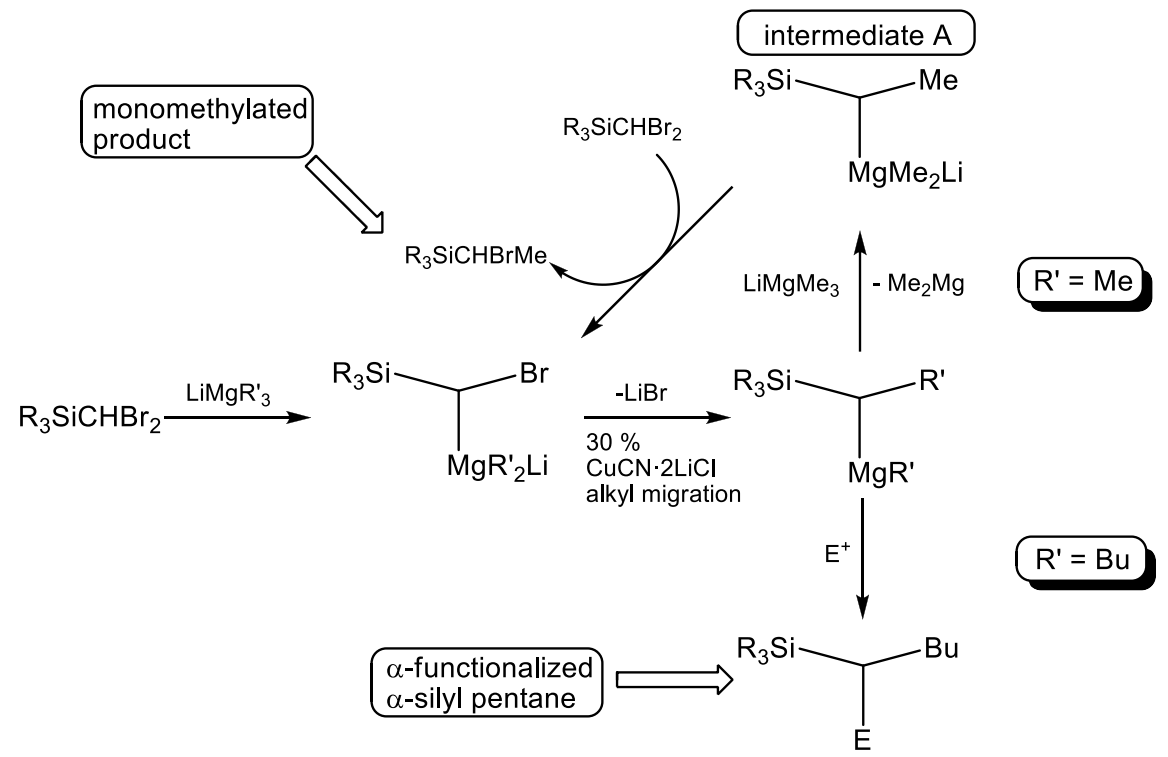

Figure 24. Contrasting reactivity of butyl versus methyl lithium magnesiates in metallation reactions of dibromomethylsilanes.

The utility of these trisalkyl lithium magnesiates for metal-halogen exchange has also been exploited for the functionalization of copolymerized bromopolystyrene beads [66].

Lithium magnesiate $\mathrm{LiMgBu}_{3}$ has been used for the smooth magnesium/bromine exchange of 5-bromo-2-methoxypyridine as an entry to the biologically active 5-substituted-2-methoxypyridines at $0{ }^{\circ} \mathrm{C}$ in THF, obtaining the desired electrophilically quenched products in reasonable yield [67]. This protocol displayed one of the major advantages of a lithium magnesiate, namely its effective utilization at more user-friendly temperatures, since the analogous lithium/bromine exchange with homometallic organolithium reagents typically requires a subambient temperature range in the same solvent.

While the majority of metal-halogen exchange reactions using $\mathrm{LiMgR}_{3}$ are carried out in situ then followed by electrophilic interception to provide new organic substrates, Oshima has also demonstrated the ability of the metallated intermediates to undergo $\mathrm{TiCl}_{4}$ mediated homo-coupling to yield bisaryl species in good yield under mild conditions [68]. 


\subsection{Polymerization}

An alternative use of alkali-metal alkyl magnesiates is as initiators of polymerization. For example, in very early work Morton discovered that the sodium magnesiate $\mathrm{NaMgBu}_{3}$ can be utilized for the polymerization of styrene with predictable molecular weights and narrow polydispersity [69]. Hsieh and co-workers also found that $\mathrm{LiMgBu}_{3}$ can be similarly exploited for the polymerization of butadiene, noting too that the homometallic $\mathrm{Bu}_{2} \mathrm{Mg}$ could not execute this effect on its own and that it was the presence of lithium which synergistically caused participation and activation of the carbon-magnesium bonds [70]. Since these initial discoveries, the scope of lithium magnesium reagents which can successfully initiate polymerization has broadened with heteroleptic alkyl/alkoxide and al$\mathrm{kyl} /$ phenoxide both being successfully used for this purpose. The former yielded isotactic-rich polystyrene (homometallic congeners contrastingly gave syndiotactic-rich polystyrene) [71] while the latter gave isoselective polymerization of methyl methacrylate [72]. Mulvey has also successfully applied the intriguing potassium (amido) magnesiate $\left[(\text { toluene })_{2} \mathrm{~K}(\text { ferrocene })_{2}\right]^{+}\left[\mathrm{Mg}(\mathrm{HMDS})_{3}\right]^{-}$(obtained from reaction of $\mathrm{KMg}(\mathrm{HMDS})_{3}$ with ferrocene) as an initiator for the polymerization of methyl methacrylate. The counter-cation seemingly plays an important role here as the high syndiotacticity content $(84 \%)$ of the polymer cannot be replicated with either $\mathrm{KMg}(\mathrm{HMDS})_{3}$ or KHMDS (44 and $31 \%$ respectively) [73].

\subsection{Magnesiates as Nucleophile Sources}

Alkali-metal alkyl magnesiates also find use as sources of nucleophilic alkyl anions. At the forefront of this research is Ishihara who demonstrated that ${\mathrm{LiMg} n \mathrm{Bu}_{3}}_{3}$ adds to a ketone in THF at $-78^{\circ} \mathrm{C}$ with superior yields to that obtained when using any of the homometallic reagents $n \mathrm{BuLi}, n \mathrm{BuMgCl}$ or $n \mathrm{Bu}_{2} \mathrm{Mg}$ [74]. No side products from reduction or aldol addition reactions were witnessed unlike in the case of the homometallic reagents (see comparison in Figure 25). In a protocol similar to that discussed in section 2, it was also noted that stoichiometric amounts of $\mathrm{LiCl}$ increased the yield further to $99 \%$. Heteroleptic ates (e.g., the mixed alkyl $\mathrm{EtMe}_{2} \mathrm{MgLi}$ ), react selectively with the ethyl group preferentially being involved in the $\mathrm{C}-\mathrm{C}$ bond formation. 


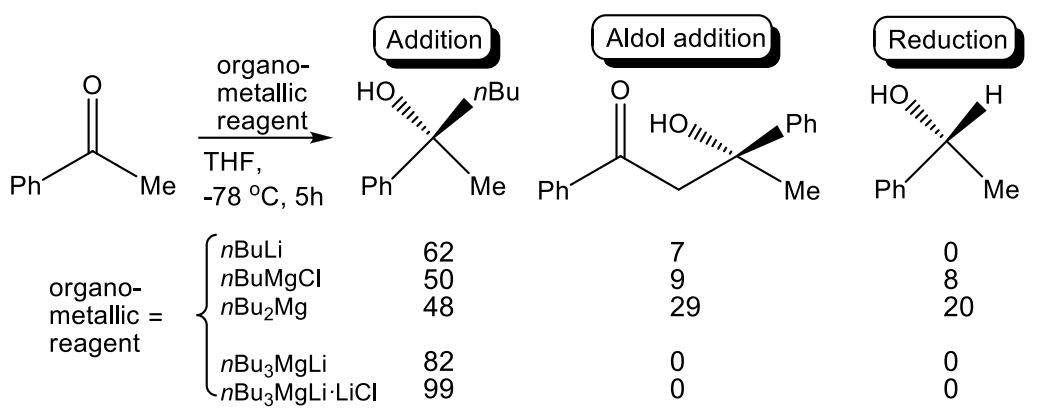

Figure 25. Comparison of various metallic reagents in their reactions with acetophenone.

Nucleophilic allylation has been achieved by Sośnicki using the generic heteroleptic allyl/bisalkyl lithium magnesiate $\mathrm{LiMgBu}_{2}$ (allyl) [75]. The substrates studied contained a piperidine ring as the common central motif, with a variety of $N$ substituted derivatives (eg $N$-lithio, $N$-alkyl, $N$-aryl, $N$-allyl) being the focus of attention. Allylation typically occurs at the 6-position (Figure 26) although the allyl group is also found on occasion at the 4-position as a result of an intramolecular Cope rearrangement which is strongly dependent on choice of reaction temperature and solvent. Various stoichiometries were studied with an (allyl) $\mathrm{MgCl}, 2 \mathrm{Bu}-$ $\mathrm{Li}$ combination [i.e. an 'ate' formulation of $\mathrm{LiMgBu}_{2}$ (allyl)] proving optimum [76]. Ring closing metathesis of the 6-allylated derivative has consequently been employed as a useful synthetic route to access the important quinolizidine skeleton [77]. 
<smiles></smiles>

$(\mathrm{X}=\mathrm{O}, \mathrm{S} ; \mathrm{R}=\mathrm{Li}, \mathrm{Me}, \mathrm{Bn}, \mathrm{Ph}$, allyl)

b)<smiles>[R]c1ccn([R])c(=O)c1</smiles><smiles>[R]C1=CC([AlH2])N([R])C(=O)C1([R])[R]</smiles>

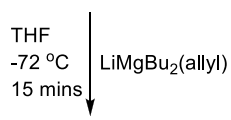
R"-X<smiles>[R]C1=CC([Al])N([R])C(=O)C1[N+](=O)[O-]</smiles>

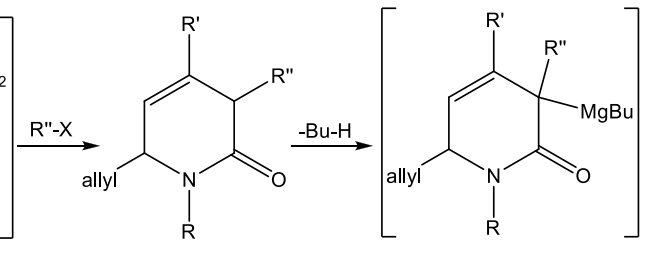
$+\mathrm{MgBu}_{2}$

Figure 26. Allylation reactions using a lithium magnesiate reagent.

Sośnicki and Struk were also able to apply their allyl/alkyl lithium magnesiate base in a one-step symmetrical double alkylation of lactams at the challenging carbon site adjacent to the carbonyl group [78]. The dual alkylation was assigned to the reactivity of $\mathrm{Bu}_{2} \mathrm{Mg}$ which was believed to be extruded after the first alkylation but is basic enough to execute a second magnesiation (Figure 26b).

Fleming elegantly demonstrated the beneficial cooperative effects between magnesium and lithium in the reaction of a cyano containing alkylmagnesium alkoxide with an aldehyde [79]. The magnesium species was found to be inert towards alkylation with $\mathrm{RCHO}$, however when $t$ BuLi was added prior to the aldehyde the alkylation reaction proceeded [80]. This modified reactivity was assigned to the in situ formation of an intermediate ate complex (Figure 27). 


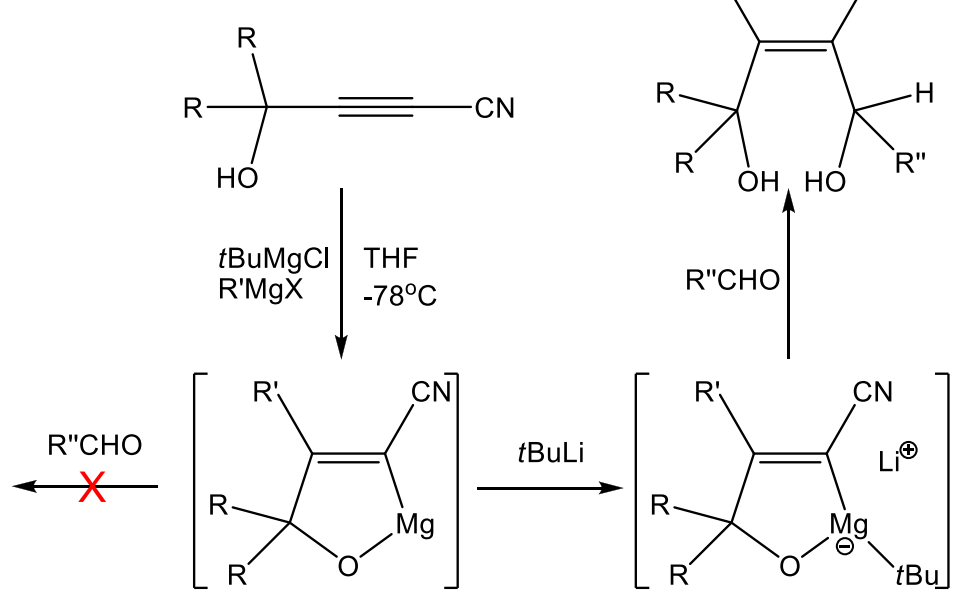

Figure 27. Lithium promoted reaction of a magnesiated substrate with an aldehyde.

Michael addition of Grignard reagents to $\alpha, \beta$-unsaturated amides and carboxylic acids has been the subject of a study by Asaoka [81]. For example, no evidence of a Michael addition product between 3-(trimethylsilyl)acrylamide and $n \mathrm{BuMgCl}$ was forthcoming in THF at room temperature; however activating the Grignard reagent with $\mathrm{MeLi}$ allowed this reaction to proceed. A variety of different Grignard reagent:MeLi ratios were studied with $1: 1$ giving only a modest yield $(7 \%)$. By adding a 2-5 fold excess of MeLi the yield was improved substantially, suggesting participation of an ate complex (Figure 28).

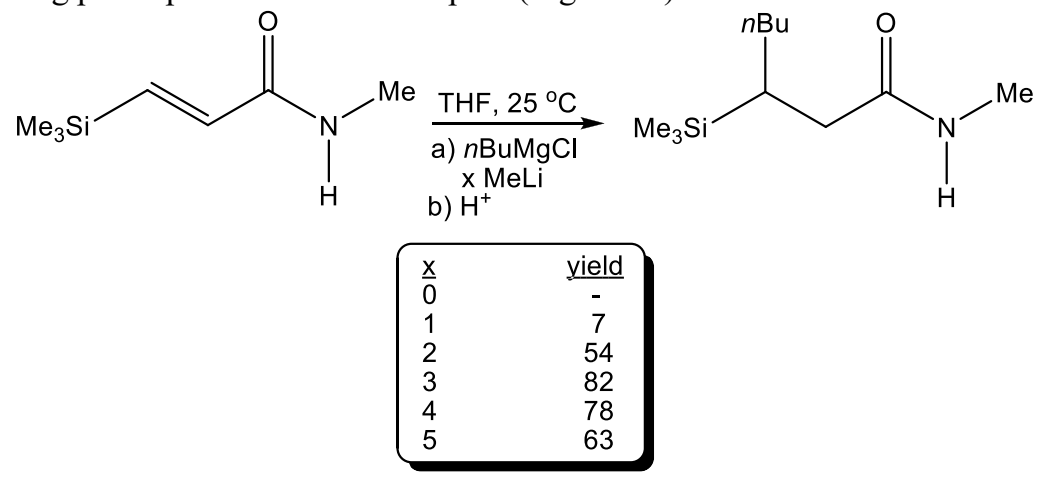

Figure 28. Effect of Grignard/organolithium reagent ratio for a Michael addition reaction. 


\subsection{Uses in Metal-Hydrogen Exchange Reactions}

One of the most useful applications of alkali-metal alkyl magnesiates is in selective deprotonative magnesiation (C- $H$ to $\mathrm{C}-\mathrm{Mg}$ exchange) of organic substrates. A major player in this research is Mongin who has studied the applicability of $\mathrm{LiMgBu}_{3}$ with a variety of organic substrates. In particular, she discovered that this base can tolerate halogen functionality in for example 3-fluoropyridine, with magnesiation occurring at the 4-position (Figure 29) which is in contrast to that witnessed with $\mathrm{BuLi} /$ Lewis donor in $\mathrm{Et}_{2} \mathrm{O}$ which metallates preferentially at the 2position $($ Lewis donor $=$ TMEDA or diazabicyclo(2,2,2)octane - DABCO) [82]. The yield of electrophilically quenched product (using 3,4,5trimethoxybenzaldehyde) was boosted from $55 \%$ to $74 \%$ by the presence of the bidentate neutral Lewis donor TMEDA. Thiophenes [83], oxazoles [84] and $[1,2,3]$ triazolo[1,5-a]pyridines [85] were likewise regioselectively deprotonated using this in situ base mixture. Interestingly, the reactivity of the thiophenes was also boosted by TMEDA involvement while that of the other two heterocyclic classes were not. Also good for atom efficiency, only $1 / 3$ of an equivalent of $\mathrm{LiMgBu}_{3}$ is required for these metallation reactions suggesting that the base reacts through all three of its anionic alkyl arms.<smiles>Fc1cccnc1</smiles><smiles>Fc1cnccc1-c1ccccc1</smiles><smiles>c1ccsc1</smiles>

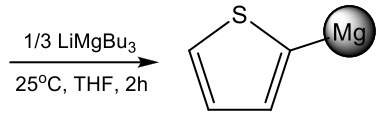<smiles>c1cocn1</smiles>

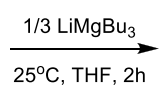<smiles></smiles><smiles>c1ccn2nncc2c1</smiles>

$1 / 3 \mathrm{LiMgBu}_{3}$ $\overrightarrow{-10^{\circ} \mathrm{C}, \mathrm{THF}, 2 \mathrm{~h}}$<smiles></smiles>

Figure 29. Regioselective magnesiations of 5- and 6-membered heterocycles using a trisalkyl magnesium base. Note only the position of magnesiation is indicated, not the full formula of the putative products. 
Mulvey, Hevia and co-workers found a similar reactivity (i.e., reactivity via all of its butyl anions) in their C-metallation of 1-methylindole with the higher order sodium magnesiate $\mathrm{Na}_{2} \mathrm{MgBu}_{4} \cdot 2 \mathrm{TMEDA}$, crystallographically characterizing the product of a $4: 1$ stoichiometric reaction as the Weiss motif $\mathrm{Na}_{2} \mathrm{Mg}$ (indol-2yl) 4 -2TMEDA [86].

Similarly, Hoarau and Marsais successfully applied the lower order ate LiMg$\mathrm{Bu}_{3}$ for the regioselective ortho-deprotonation of (4',4'-dimethyloxazolin-2yl)benzene, with the reaction proceeding at synthetically desirable room temperature in THF [87].

\subsection{Contrasting Reactivity of Higher-Order and Lower-Order Alkyl Magnesiates}

The differing reactivity of these stoichiometrically distinct magnesiates was recognised by Mulvey who compared the reactivity of the sodium alkyl magnesiates $\mathrm{NaMgBu}_{3}$ and $\mathrm{Na}_{2} \mathrm{MgBu}_{4}$ in the presence of the Lewis donor DABCO towards the deprotonative metallation of toluene (Figure 30a) [88]. Interestingly the higherorder magnesiate yielded a sodiated benzyl complex while the lower order complex gave a DABCO- and toluene-solvated contact-ion pair in which no deprotonation to benzyl anions takes place. 


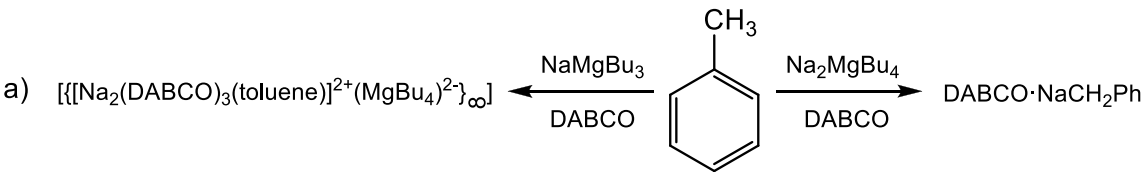

b)<smiles></smiles>

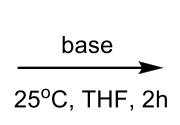<smiles>Cc1cccc(-c2ccco2)c1</smiles><smiles>Ic1ccco1</smiles>

c)<smiles>CCCCNC(=O)c1ccnc(Cl)c1</smiles><smiles>CCCCNC(=O)c1cc(Cl)ncc1-c1ccccc1</smiles>
base $=\mathrm{Li}_{2} \mathrm{MgBu}_{4} \quad 90 \%$ base $=\mathrm{LiMgBu}_{3} \quad 75 \%$

Mongin also noted and quantified a reactivity difference between higher-order $\mathrm{Li}_{2} \mathrm{MgBu}_{4}$ and lower-order $\mathrm{LiMgBu}_{3}$ in the regioselective deprotonation of furan; while both bases deprotonated at the same site, the higher order magnesiate gave an improved yield under identical reaction conditions (Figure 30b) [89]. Likewise, Marsais and co-workers saw a similar yield increase under identical conditions on moving from lower order to higher order magnesiate in the deprotonation of 2chloro- $N$-tert-butylisonicotinamide (Figure 30c) with the yield improving from 42 (39) to 80 (66) \% upon electrophilic interception with $\mathrm{D}_{2} \mathrm{O}$ (or $\mathrm{I}_{2}$ ) [90].

Substituting homoleptic alkyl reagents by heteroleptic alkyl/amido reagents, Mongin reported the deprotonation of 4-chloropyridine at $-10{ }^{\circ} \mathrm{C}$ in THF solution, evidenced via electrophilic trapping with iodine, using higher-order $\mathrm{Li}_{2} \mathrm{MgBu}_{3}$ (TMP). Both homoleptic and heteroleptic lower-order lithium magnesiates [namely $\mathrm{LiMgBu}_{3}$ and $\mathrm{LiMgBu}_{2}$ (TMP) respectively] failed to facilitate such a reaction under identical conditions [91]. 


\subsection{Synthetic Applications using Magnesium Zincates}

A recently emerging form of heterometallic magnesium reagent in synthesis is the so called magnesium/zinc hybrid reagent, a name coined by Hevia. Not usually recognised as bimetallic reagents but more as magnesium and zinc compound mixtures, these tend to display lower reactivity than the alkali-metal/magnesium or alkali-metal/zinc species due to the absence of the highly reactive alkali-metal component, which can be credited with 'boosting' the reactivity of the accompanying divalent metal through anionic (ate) activation. Nevertheless, $\mathrm{Mg} / \mathrm{Zn}$ reagents have recently found use in a number of synthetic applications with a few of the highlights summarized below.

Ishihara studied the alkylation of ketones using a variety of Grignard reagents and additives [92-93], finding that ethylation of benzophenone with $\mathrm{EtMgCl}$ was significantly enhanced by the presence of $\mathrm{ZnEt}_{2}$ (Figure 31) [94]. Indeed, the reactive bis-alkyl zinc reagent could be replaced by the salt $\mathrm{ZnCl}_{2}$ with no diminishment of conversion. Only $10 \mathrm{~mol} \%$ of the zinc additives were necessary for the improvement to take place, indicative of a catalytic process. Not only was the yield of the desired tertiary alcohol product improved, but the amount of undesirable reduction product was inhibited.
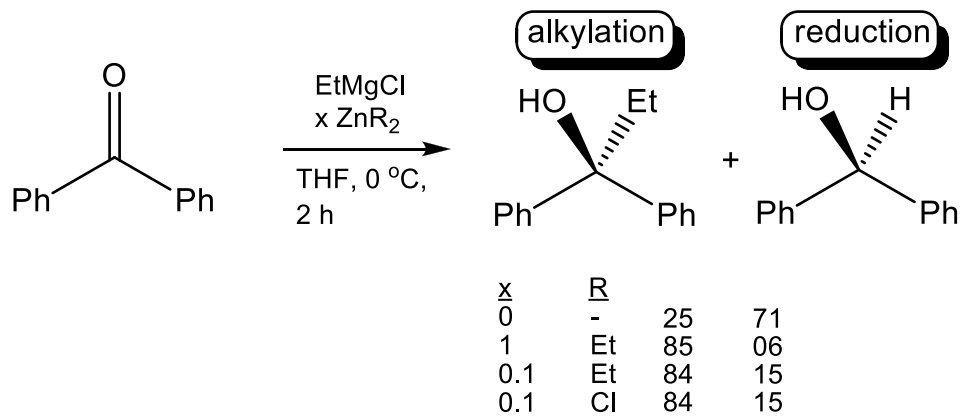

Figure 31. Influence of a zinc reagent on reaction of a Grignard reagent with benzophenone.

Similar methodology has been applied to the alkylation of chlorosilanes to form new silicon-carbon bonds [95]. While these reactions proceed smoothly, when carried out with organolithium reagents low temperature regimes are required; similarly the same reactions with less efficient homometallic organomagnesium reagents require heat and prolonged reaction times for comparable reactivity. As little as $1 \mathrm{~mol} \%$ of $\mathrm{ZnCl}_{2} \cdot$ TMEDA is sufficient to promote these reactions with for example the yield of product obtained from chlorodimethylphenylsilane and paratolylmagnesium bromide in THF being improved from 13 to 67 or $77 \%$ by adding $\mathrm{ZnCl}_{2}$ or $\mathrm{ZnCl}_{2} \cdot \mathrm{TMEDA}$. Studte and Breit noticed a significant effect on adding 
zinc additives in their cross-coupling studies of Grignard reagents with $\alpha$-hydroxy ester triflates to yield enantiopure products [96]. In the absence of a second metallic co-reagent, problems such as nucleophilic addition of the chloride rather than the alkyl anion, homocoupling or reduction of the triflate functionality inhibited the purity and yield of the desired product ( $46 \%$ yield, $62 \%$ e.e.). However, in the presence of $5 \mathrm{~mol} \%$ of $\mathrm{ZnCl}_{2}$ a near quantitative yield of the desired ester product was obtained with complete inversion of configuration (Figure 32). Using the chloro-Grignard reagent was found to be of high importance since $n \mathrm{BuMgBr}$ diminished the yield to only $11 \%$ under identical conditions. Impressively, yields were continually greater than $90 \%$ with e.e. values greater than $99 \%$ when the reaction was extended to other alkyl Grignard reagents.<smiles>CCC(C)OC(=O)[C@@H](C)O</smiles>

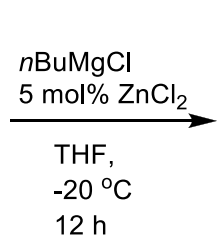<smiles>CCCCOC(=O)C(C)CCCC</smiles>

Figure 32. Catalytic effect of $\mathrm{ZnCl}_{2}$ on the cross-coupling reaction of a Grignard reagent with $\alpha$ hydroxy ester triflates.

Shedding light on the structures involved in, and thereby increasing understanding of magnesium zincate hybrid induced reactions, Hevia crystallographically characterized the bimetallic product obtained from adding a sub-stoichiometric amount of $\mathrm{ZnCl}_{2}$ to $t \mathrm{BuMgCl}$ in THF as the solvent separated ion pair $\left[\mathrm{Mg}_{2} \mathrm{Cl}_{3}(\mathrm{THF})_{6}\right]^{+}$ $\left[\mathrm{Zn} t \mathrm{Bu}_{3}\right]^{-}$(Figure 33) [97]. In synthesis, she found that this heterometallic trisalkylzincate was active towards three molar equivalents of 4-iodotoluene via metal-halogen exchange to generate a tris-aryl zincate which is an effective precursor in Negishi cross-coupling reactions. Significantly, these structural studies revealed that though present in only sub-stoichiometric amounts, it is the zinc which is the 'active' metal, although the magnesium clearly plays an important secondary role in the overall reaction since such reactivity could not be accessed by a dialkyl zinc or zinc halide reagent on its own. 


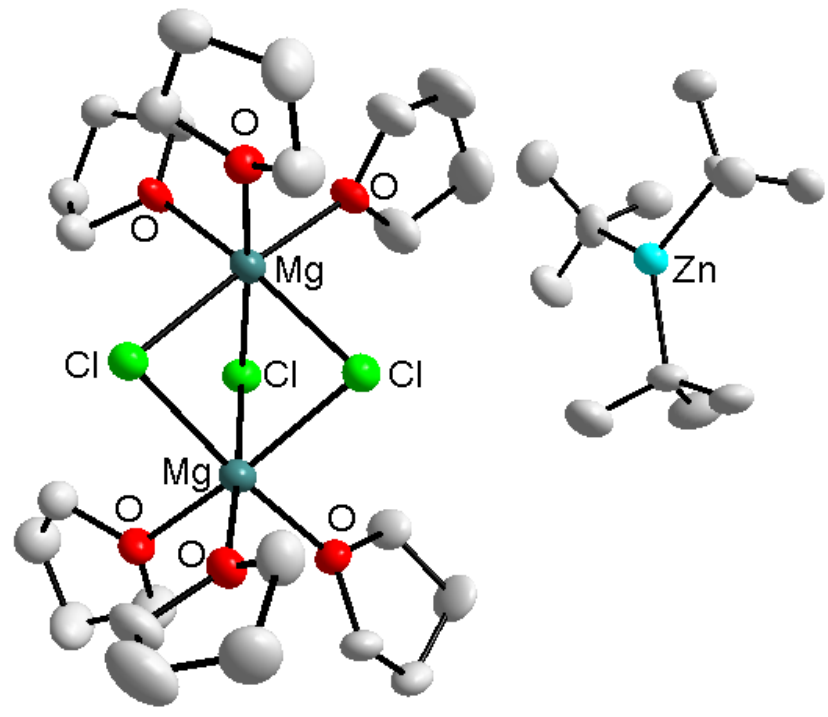

Figure 33. Molecular structure of the solvent separated magnesium-zinc hybrid reagent $\left[\mathrm{Mg}_{2} \mathrm{Cl}_{3}(\mathrm{THF})_{6}\right]^{+}\left[\mathrm{Zn} t \mathrm{Bu}_{3}\right]^{-}$with hydrogen atoms omitted for clarity.

Surprisingly, simply changing the Grignard reagent from $t \mathrm{BuMgCl}$ to $\mathrm{EtMgCl}$ and reacting it in a 3:1 ratio with $\mathrm{ZnCl}_{2}$ gave a zinc-rich solvent separated metathesis product formulated as $\left[\mathrm{Mg}_{2} \mathrm{Cl}_{3}(\mathrm{THF})_{6}\right]^{+}\left[\mathrm{Zn}_{2} \mathrm{Et}_{5}\right]^{-}$[98]. The product obtained upon reacting this heterometallic species with benzophenone was identified as homometallic $\left[\mathrm{Mg}_{2} \mathrm{Cl}_{3}(\mathrm{THF})_{6}\right]^{+}\left[\mathrm{Mg}_{2}\left(\mathrm{OC}(\mathrm{Et}) \mathrm{Ph}_{2}\right)_{2} \mathrm{Cl}_{3}(\mathrm{THF})\right]^{-}$with $\mathrm{Et}_{2} \mathrm{Zn}$ being coproduced and thus recycled, an important observation in the context of trying to rationalise the catalytic properties of the zinc component. The outcome of this reaction showcases the importance of the cooperative effect between the two metals since reduction of the ketone is observed using $\mathrm{EtMgCl}$ in the absence of $\mathrm{ZnCl}_{2}$.

A more complicated trimetallic $\mathrm{Mg} / \mathrm{Zn} / \mathrm{Li}$ cooperativity has been implicated by Hevia and her team in their studies of magnesium/zinc hybrids with the sensitive fluorinated ketone trifluoroacetophenone [99]. They determined that their hybrid formulated as $\left[(\mathrm{THF})_{2} \mathrm{Mg}(\mu-\mathrm{Cl})_{3} \mathrm{ZnEt}\right]_{2}$ was a poor reagent for the alkylation of the ketone, yet the same hybrid in the presence of a stoichiometric amount of $\mathrm{LiCl}$ (initiating a $\mathrm{Mg} / \mathrm{Zn} / \mathrm{Li}$ tri-cooperativity) permitted the desired reaction to proceed in $74 \%$ yield with concomitant diminishing of the amount of undesirable reduction products/recovered starting material (Figure 34). 


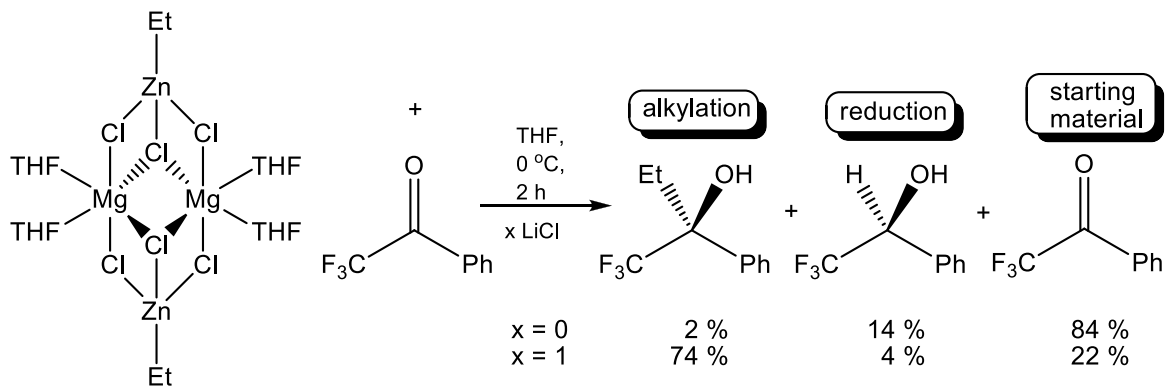

Figure 34. Influence of $\mathrm{LiCl}$ on outcome of reaction between a $\mathrm{MgZn}$ hybrid reagent and trifluoroacetophenone.

\subsection{Heteroleptic Alkyl/Amido Alkali-Metal Magnesiates}

Magnesium heterometallic bases containing a mixed organo-ligand set constitute another distinct class of magnesium reagent (mixed organo-ligand set in this context means ligands belonging to two distinct categories of ligand as opposed to those compounds for example $\mathrm{LiMgBu}_{2} \mathrm{Me}$ which although heteroleptic contain only one type of ligand, namely alkyl groups in this instance). The most studied species within this context are alkali-metal magnesiates containing a mixture of alkyl and secondary amide $\left(\mathrm{R}_{2} \mathrm{~N}\right)$ ligands. Because of the heteroleptic nature of these complexes, research in this area has seen considerable focus fall upon the constitution of the intermediate products, since a heteroleptic reagent clearly has more than one type of anion available for any given reaction. A clear understanding of the intermediate products in any multi-step reaction can provide considerable insight into a number of facets including most obviously reactivity, selectivity and reaction mechanisms and can greatly aid the synthetic chemist in either the understanding of observed chemistry or the design of future work.

Mixed ligand-set alkali-metal magnesiates are typically prepared via a cocomplexation route (Figure 35a), whereby pre-existing sigma bonds between metals and ligands remain intact, but the individual components come together via secondary bonding to produce the new framework. Also typically present on the alkali-metal is a co-ordinatively saturating neutral Lewis donor which prevents polymerization, providing a discrete molecular species which is generally soluble in common organic solvents. These heterobimetallic complexes can effectively be considered as "hemi-Weiss motifs" see section 3.1) since there are no longer any anions bridging two magnesium centres or bridging one magnesium centre to two alkali metal centres. When a bidentate anion is utilized rather than co- 
complexation occurring, insertion of the magnesium reagent into the alkali-metal anion bond can occur (Figure 35b) [100].

a)

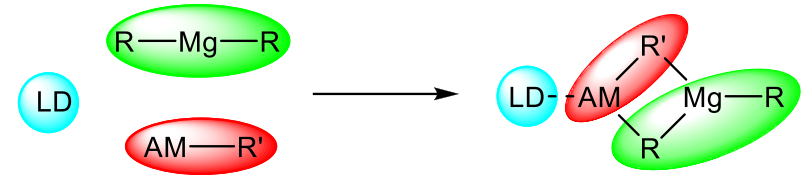

b)

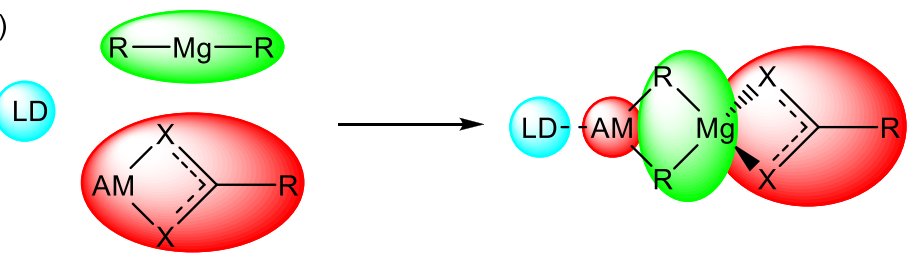

Figure 35. Schematic examples of a) co-complexation and b) insertion routes to mixed-ligand alkali-metal magnesiates. Note that possible aggregation of the starting organometallics is not taken into account in this simplified depiction.

The main use of magnesium heterometallic reagents such as these is in the selective deprotonative metallation reaction of organic substrates. The recurring theme, emphasised via the following representative examples, is that both metals must be present for the observed reactivity to occur (either component part on its own is typically unreactive or gives a different selectivity) and that it is the formally lessreactive metal (in a conventional homometallic sense), magnesium, which carries out the metallation (although its reactivity has clearly been boosted by the presence of and the electronic input and redistribution caused by the reactive alkalimetal component).

Varying the individual components even slightly can have a profound influence on the resulting deprotonative metallation reaction. For example, the Lewis donor free base mixture formulated as $\mathrm{NaMg} n \mathrm{Bu}(\mathrm{TMP})_{2}$ will remarkably double deprotonate the aromatic substrates benzene or toluene at the 1,4 and 2,5 positions, respectively [101]. This reactivity can clearly be attributed to the group 1 and 2 metals working in unison since these results cannot be replicated by either of the constituent parts of the base. Of particular note here is that toluene is prone to undergoing metallation at the methyl arm to give a benzyl anion (an example of thermodynamic acidity), which is energetically most favourable due to resonance stabilization, but surprisingly treatment with this bimetallic base does not involve the methyl arm (figure 36). The reactivity of the base $\mathrm{NaMg} n \mathrm{Bu}(\mathrm{TMP})_{2}$ is modified by the addition of TMEDA to the reactive co-complex; the result being only monodeprotonation of the arenes [102] (surprisingly at the meta position in the case of toluene). Changing the identity of the alkyl anion simply from $n \mathrm{Bu}$ to $t \mathrm{Bu}$ 
(whilst still in the presence of TMEDA) reverts the deprotonation of benzene back to 1,4-dideprotonation [103]. Finally, using the silyl substituted neopentyl mimic $\mathrm{CH}_{2} \mathrm{SiMe}_{3}$ in place of a butyl group in $\mathrm{NaMg}\left(\mathrm{CH}_{2} \mathrm{SiMe}_{3}\right)(\mathrm{TMP})_{2}$ results in dideprotonation of toluene but this time at the 3 and 5 positions (see Figure 36) [104] The implication is that steric factors dictate this change of regioselectivity. What is clear from structural studies is that it is a magnesiation reaction that has taken place, with the $\mathrm{Mg}$ centres preferentially forming $\sigma$ bonds with the aromatic carbon atoms and the sodium centres lying in a stabilizing $\pi$-bound position.

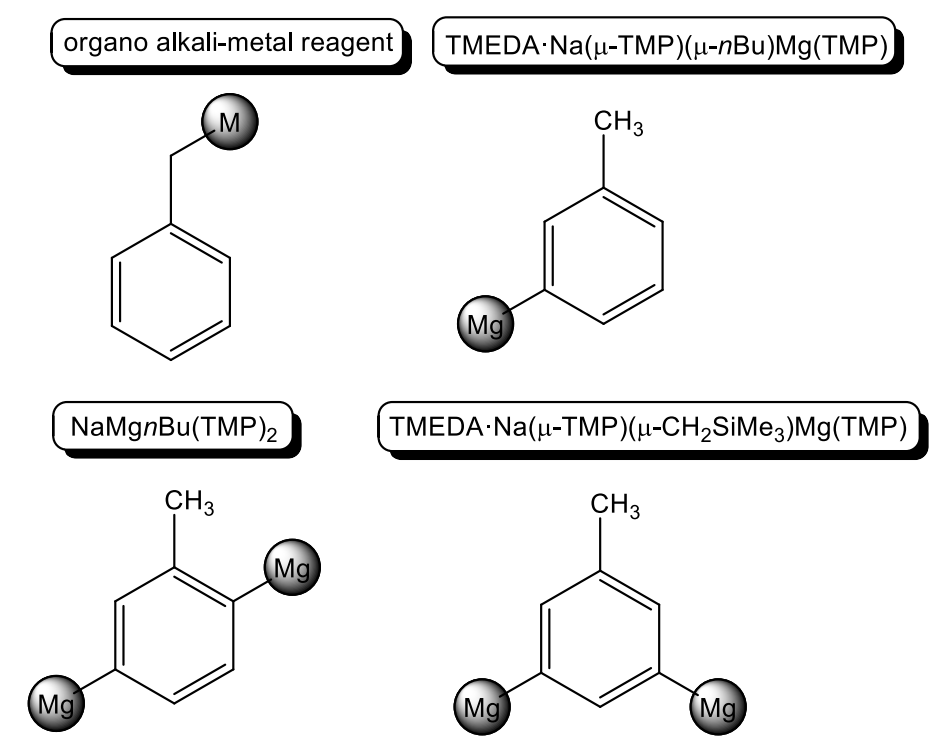

Figure 36. Different deprotonation sites of toluene effected using the various metallic bases shown in the boxes.

These novel areneide and arenediide anions are typically found within a larger molecular framework, encapsulated by a "host" ring of metal cations and organic anions. The host ring itself carries a formal positive charge to balance the negative charge of the central deprotonated "guest" substrate and these species are referred to as 'inverse crowns' to reflect the antithetical nature of their structural make up with regards to a typical crown ether structure which contrastingly involves a central cationic species (e.g. a discrete $\mathrm{Li}^{+}$or $\mathrm{Na}^{+}$cation) encapsulated by a ring containing Lewis donating heteroatoms. Originally seen for heterometallic monovalent/divalent metal combinations, inverse crown chemistry has now been extended to include homometallic group 1 examples comprising solvent-separated ion pairs with host ring a neutral entity which traps a halide anion [105].

While not taking a direct role in the metallation, the choice of alkali-metal is still of paramount importance as demonstrated on changing the bimetallic base from 
$\mathrm{NaMgBu}(\mathrm{TMP})_{2}$ to $\mathrm{KMgBu}(\mathrm{TMP})_{2}$. As previously mentioned, the former results in a 12-membered $\left(\mathrm{Na}_{4} \mathrm{Mg}_{2} \mathrm{~N}_{6}\right)$ inverse crown with a single arenediide encapsulated as the guest; however the potassium congener only executes a single deprotonation of the same substrate, with the result being a 24 -membered $\left(\mathrm{K}_{6} \mathrm{Mg}_{6} \mathrm{~N}_{12}\right)$ inverse crown encapsulating six individual areneide molecules (Figure 37) [106]. This represents the largest inverse crown known to date.
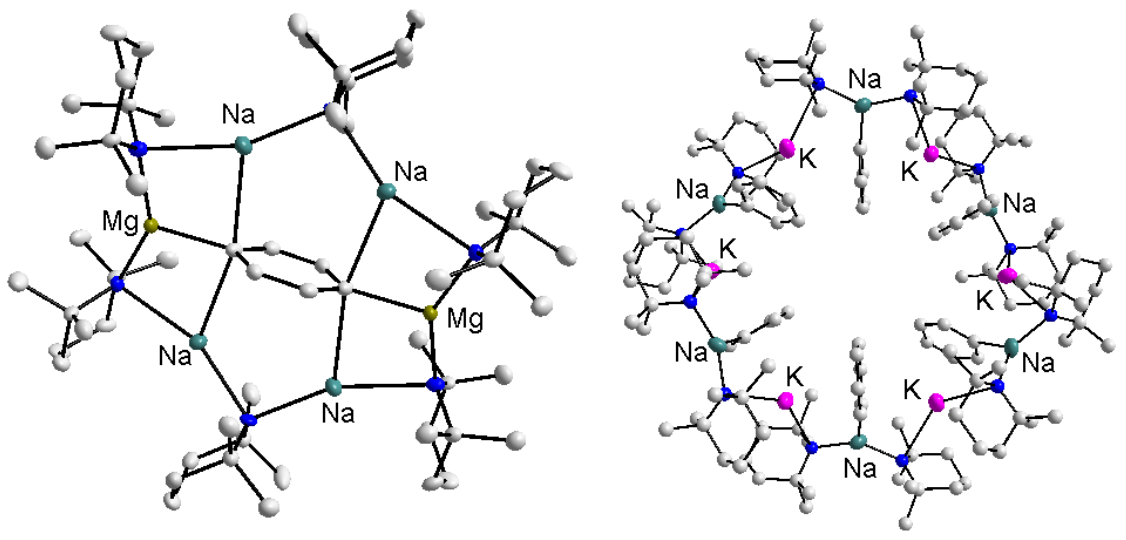

Figure 37. Molecular structures of $\mathrm{Na} / \mathrm{Mg}$ (left) and $\mathrm{K} / \mathrm{Mg}$ (right) TMP inverse crowns with one $\left(\mathrm{C}_{6} \mathrm{H}_{4}\right)^{2-}$ and six $\left(\mathrm{C}_{6} \mathrm{H}_{5}\right)^{-}$guest molecules respectively.

A particularly spectacular demonstration of the direct magnesiation of aromatic species via an alkali-metal magnesiate base is witnessed in the reaction of the tris(diisopropylamide) $\mathrm{NaMg}\left(\mathrm{N} i P r_{2}\right)_{3}$ with the series of group 8 parent metallocenes ferrocene [107], ruthenocene and osmocene [108]. These mixtures generate a 16-atom $\left(\mathrm{Na}_{4} \mathrm{Mg}_{4} \mathrm{~N}_{8}\right)$ inverse crown made up of metal-diisopropylamide-metal

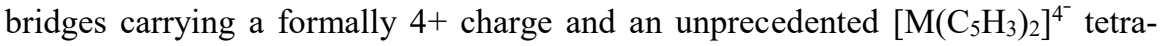
anionic guest at its core $(\mathrm{M}=\mathrm{Fe}, \mathrm{Ru}$, or Os - Figure 38). This eyecatching outcome showcases the cooperative effect between the two metals since a metallocene cannot generally be metallated at more than 2 of its 10 potential sites in a controlled manner, and certainly not with the homometallic constituents of the heterometallic base, $\mathrm{NaNi} \mathrm{Pr}_{2}$ or $\mathrm{Mg}\left(\mathrm{Ni}_{2} \mathrm{Pr}_{2}\right)_{2}$. Further, the products clearly display $\mathrm{Mg}-\mathrm{C} \sigma$-bonds, making this the first example of direct magnesiation of a metallocene, whether by a homometallic or heterometallic reagent. 


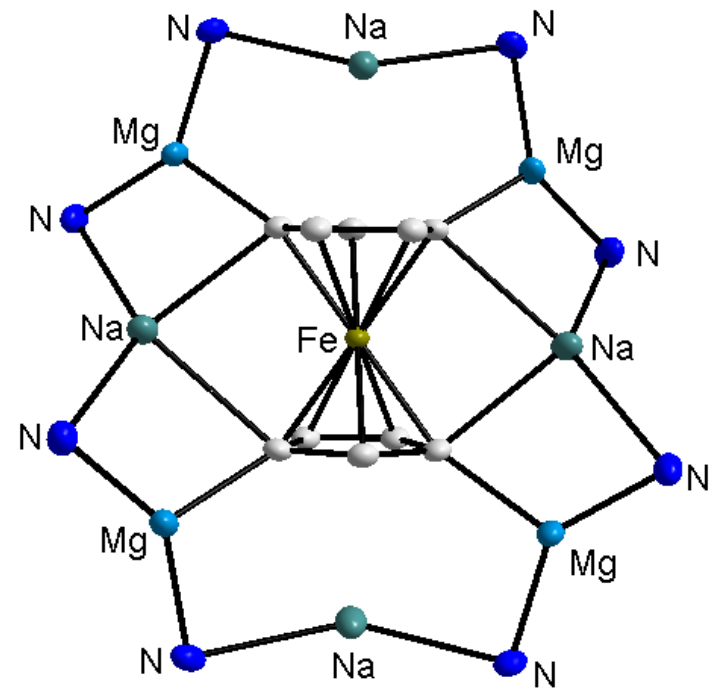

Figure 38. Molecular structure of the tetrasodium-dimagnesium inverse crown $\left[\mathrm{Na}_{4} \mathrm{Mg}_{4}\left(\mathrm{NiPr}_{2}\right)_{8}\right]^{4+}$ with $\left[\left(\mathrm{C}_{5} \mathrm{H}_{3}\right)_{2} \mathrm{Fe}\right]^{4-}$ core. All carbon atoms of amide groups and all hydrogen atoms have been omitted for clarity.

The importance of the alkali-metal identity is illustrated once more by the reactivity of the homoleptic bimetallic amido bases $\operatorname{MMg}\left(\mathrm{NiPr}_{2}\right)_{3}(\mathrm{M}=\mathrm{Li}, \mathrm{Na})$ towards phenylacetylene [109]. The lighter alkali-metal congener will deprotonate two molar equivalents of substrate resulting in a linear dimeric, tetranuclear complex formulated as [(TMEDA) $\left.\operatorname{LiMg}(\mathrm{C} \equiv \mathrm{CPh})_{2}\left(\mathrm{NiPr}_{2}\right)\right]_{2}$; while the sodium derivative will deprotonate a single molar equivalent of alkyne to yield a product of formula $\left[\mathrm{NaMg}(\mathrm{C} \equiv \mathrm{CPh})(\mathrm{NiPr})_{2}\right]_{2}$ with an inverse crown motif.

As mentioned earlier, heteroleptic bases have the potential to react via any of their distinct anions making structural tracking an important facet for gaining a true understanding of the chemisty. This was clearly illustrated by Mulvey and coworkers who designed a heteroleptic potassium magnesiate, PMDETA $\mathrm{K}(\mu-$ TMP)( $\left.\mu-\mathrm{CH}_{2} \mathrm{SiMe}_{3}\right) \mathrm{Mg}(\mathrm{TMP})$, via the aforementioned co-complexation strategy [110]. Studied with the aromatic ether molecule anisole (PhOMe), this base was found to deprotonate this substrate on the aromatic ring, ortho to the lateral methoxy group in a regioselectivity conforming to the well established principles of directed ortho metallation $(\mathrm{D} o \mathrm{M})$ chemistry. An interesting feature of this study was that two products were apparent, heterotrianionic PMDETA $\mathrm{K}\left(\mu-\mathrm{MeOC}_{6} \mathrm{H}_{4}\right)(\mu-$ $\left.\mathrm{CH}_{2} \mathrm{SiMe}_{3}\right) \mathrm{Mg}(\mathrm{TMP})$ and heterodianionic PMDETA·K $(\mu-\mathrm{TMP})(\mu-$ $\left.\mathrm{MeOC}_{6} \mathrm{H}_{4}\right) \mathrm{Mg}(\mathrm{TMP})$, that is starting from the base one where TMP $(\mathrm{H})$ has been lost (through amido deprotonation) and the other where $\mathrm{SiMe}_{4}$ has been lost (through alkyl deprotonation). A time-dependent NMR spectroscopic study established that the former is the kinetic product while the latter is the thermodynamic 
product. The TMP $(\mathrm{H})$ amine which is extruded upon deprotonation of the substrate is not sufficiently volatile to be lost to the system and being relatively acidic $\left(\mathrm{p} K_{\mathrm{a}}=37\right)$ it is then deprotonated by the $\mathrm{Me}_{3} \mathrm{SiCH}_{2}{ }^{-}$of the kinetic intermediate to give the final thermodynamic product (Figure 39).

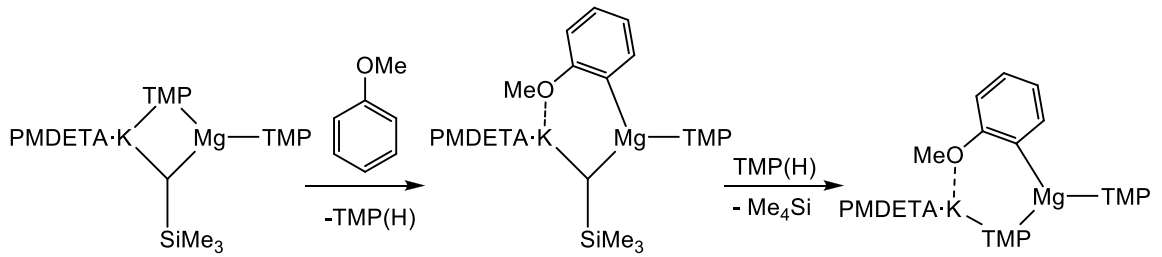

Figure 39. Kinetic/thermodynamic products obtained from reaction of a heteroleptic potassium magnesiate with anisole.

The TMEDA-solvated sodium derivative of this base [TMEDA $\cdot \mathrm{Na}(\mu-\mathrm{TMP})(\mu-$ $\left.\left.\mathrm{CH}_{2} \mathrm{SiMe}_{3}\right) \mathrm{Mg}(\mathrm{TMP})\right]$ has also been used in one of the most spectacular demonstrations of the ability of heterometallic reagents to effect unusual deprotonations, namely in the 'cleave-and-capture' of the cyclic ether THF [111]. While the deprotonation of THF is not uncommon with homometallic bases (in fact often seen as an unwanted side reaction when THF is employed as a solvent in organometallic chemistry), the proximity of the developed negative charge to the electron rich oxygen atom typically results in a spontaneous ring opening of the anion into ethene and the enolate of acetaldehyde. However, by using the aggressive sodium magnesiate, the THF molecule is cleaved to an $\mathrm{O}^{2^{-}}$and a (butadienide) ${ }^{2^{-}}$through the formal loss of four protons, with the two dianionic fragments being simultaneously captured within heterometallic frameworks, an oxo inverse crown for the former and a tetranuclear complex for the latter (Figure 40).

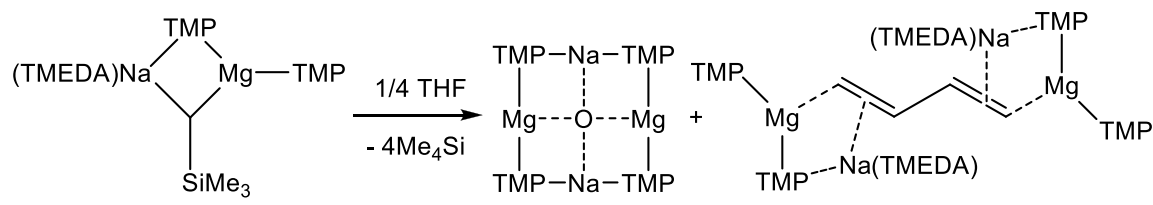

Figure 40. Cleave and capture chemistry executed by a sodium magnesiate on the cyclic ether THF.

While this magnesium based reaction involves cleavage of the sensitive THF ring followed by capture of the parts, it should be noted more "compassionAte" alkali metal zinc [112] and alkali metal aluminium reagents [113] $\alpha$-deprotonate THF without opening the ring, with the resulting cyclic anion being captured. This clearly highlights the differing reactivity of these metals when used in conjunction with an alkali-metal and showcases the importance of carefully tailoring the bimetallic base. 
Finally, in a remarkable new concept for a magnesiate system, Hevia and coworkers have recently reported an intriguing cascade reaction converting benzothiazole into a novel trianionic derivative with an N-C-C-C-N delocalized ligation centre. This conversion involves sequential deprotonation, $\mathrm{C}-\mathrm{C}$ coupling, ring opening and nucleophilic addition steps (Figure 41) [114]. This reaction was achieved by first converting the homoleptic sodium magnesiate $\mathrm{NaMgBu}_{3}$ into the solvent-separated magnesiate $\left[\mathrm{Na}(\mathrm{THF})_{6}\right]^{+}\left[\mathrm{BuMg}(\mathrm{NR})_{2} \mathrm{SiPh}_{2} \cdot \mathrm{THF}\right]^{-}(\mathrm{R}=2,6-$ diisopropylphenyl) by deprotonation of the bis-amine (HNR) ${ }_{2} \mathrm{SiPh}_{2}$. This style of cascade reaction is normally more associated with redox-active transition or lanthanide metals, so its emergence here in magnesium chemistry could open up a promising new line of research.

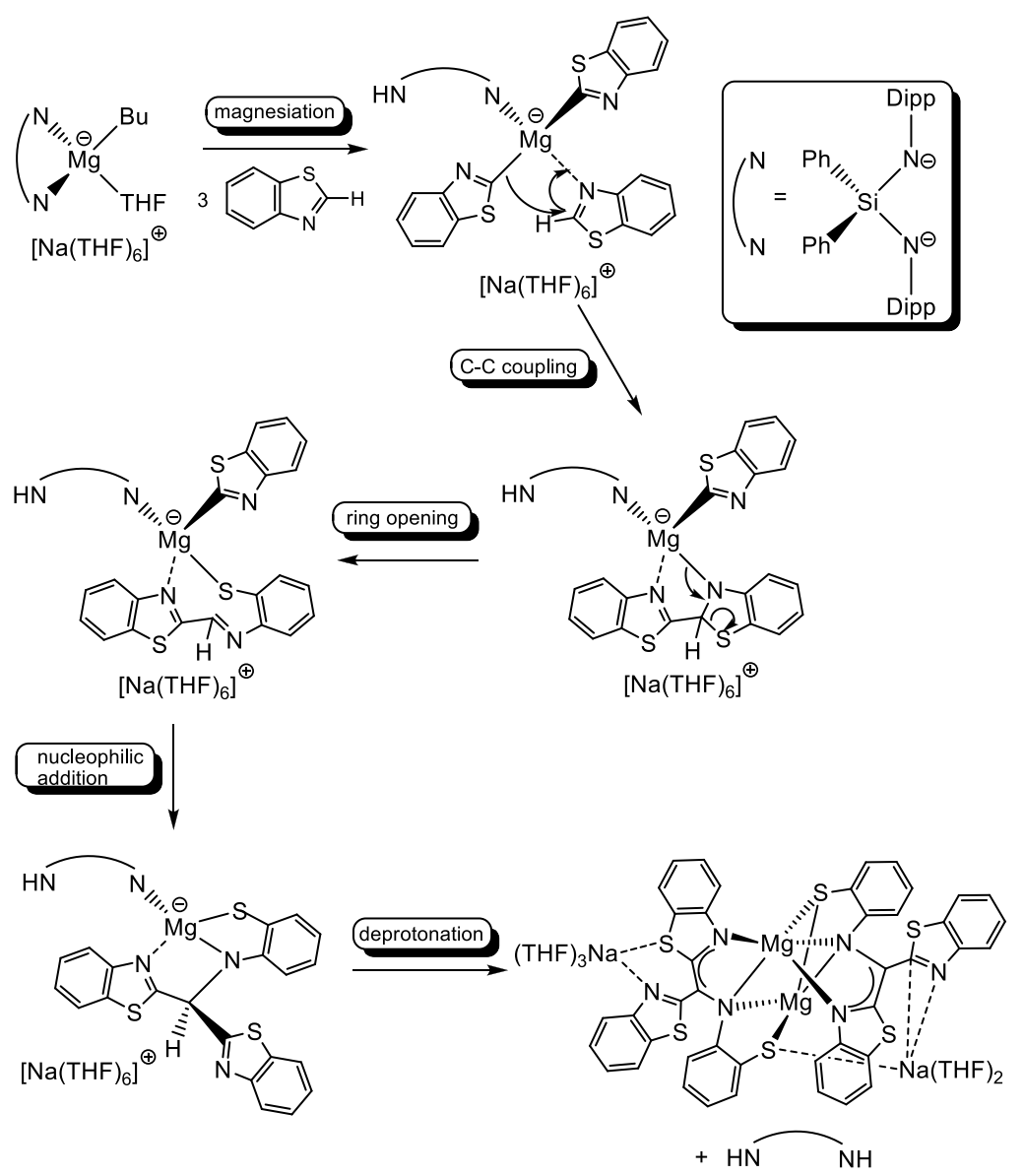

Figure 41. Cascade reaction of a sodium magnesiate towards the important heterocycle benzothiazole. 


\section{Conclusion}

Considering it was invented at the beginning of the $20^{\text {th }}$ century, organomagnesium reagent chemistry has retained its usefulness for a remarkably long time and amazingly in 2012 its usefulness is still growing. Every chemist from a young undergraduate to a career industrialist is familiar with the classical Grignard reagents. There have been numerous developments in this chemistry over the past one hundred years but arguably the past ten or so years has seen the most significant subject-transforming advances. Previously organomagnesium reagents, known for their mild reactivity which made them excellent tools for nucleophilic addition reactions, had to defer to their more reactive organolithium rivals when faced with more challenging metal-halogen or metal-hydrogen exchange applications. With the advent of Turbo-Grignard reagents and Turbo-Hauser reagents, where classical organomagnesium reagents are activated by reactivity boosting salt (commonly lithium chloride) additives, new magnesium-halogen and magnesium-hydrogen methodologies have emerged that offer substantial benefits over established organolithium methods. Ate formulations made by combining organomagnesium compounds with other organometallic compounds (for example, most typically organolithiums or organosodiums) can also exhibit strikingly different chemistry in terms of both reactivity and regioselectivity compared to that of classical organomagnesium reagents. Clearly co-operative effects between the different components provide the key to the improved reactivity of these new types of multicomponent organomagnesium reagents. Further studies will be needed to gain a more complete understanding of how these co-operative effects operate and how we can best tune them for forthcoming synthetic campaigns. A grand challenge will be to transform these stoichiometric reagents into substoichiometric or better still catalytic reagents.

Acknowledgements We wish to thank the EPSRC, Royal Society (Wolfson research merit award to REM), Nuffield Foundation and EU for generous sponsorship allowing us to pursue our interests in magnesium chemistry and to all past and present members of the Mulvey research group for their excellent contributions to these studies as well as for their friendship.

\section{References}

1. Grignard V (1901). Ann Chim 24:433

2. Seyferth D (2009). Organometallics 28:1598 
3. Tidwell TT (2001). Angew Chem Int Ed 40:331

4. Schlenk W, Schlenk Jr. W (1929). Chem Ber 62:920

5. Meunier L (1903). C R Hebd Seances Acad Sci 136:758

6. Hauser CR, Walker Jr HG (1947). J Am Chem Soc 69:295

7. Frostick Jr FC, Hauser CR (1949). J Am Chem Soc 71:1350

8. Hauser CR, Yost RS, Ringler BI (1949). J Org Chem 14:261

9. Olofson RA, Dougherty CM (1973). J Am Chem Soc 95:581

10. Lappert MF, Slade MJ, Singh A, Atwood JL, Rogers RD, Shakir R (1983). J Am Chem Soc 105:302

11. Eaton PE, Lee C-H, Xiong Y (1989). J Am Chem Soc 111:8018

12. Schlecker W, Huth A, Ottow E, Mulzer J (1995). J Org Chem 60:8414

13. Kondo Y, Yoshida A, Sakamoto T (1996). J Chem Soc, Perkin Trans 1:2331

14. Shilai M, Kondo Y, Sakamoto T (2001). J Chem Soc, Perkin Trans 1:442

15. Barr L, Kennedy AR, MacLellan JG, Moir JH, Mulvey RE, Rodger PJA (2000). Chem Commun: 1757

16. Kawachi A, Nagae S, Onoue Y, Harada O, Yamamoto Y (2011). Chem Eur J 17:8005

17. Whisler MC, MacNeil S, Snieckus V, Beak P (2004). Angew Chem Int Ed 43:2206

18. Gupta L, Hoepker AC, Singh KJ, Collum DB (2009). J Org Chem 74:2231

19. Ma Y, Hoepker AC, Gupta L, Faggin MF, Collum DB (2010). J Am Chem Soc 132:15610

20. Krasovskiy A, Knochel P (2004). Angew Chem Int Ed 43:3333

21. Baron O, Knochel P (2005). Angew Chem Int Ed 44:3133

22. Ren H, Krasovskiy A, Knochel P (2004). Org Lett 6:4215

23. Ren H, Krasovskiy A, Knochel P (2005). Chem Commun:543

24. Krasovskiy A, Krasovskaya V, Knochel P (2006). Angew Chem Int Ed 45:2958

25. García-Álvarez P, Graham DV, Hevia E, Kennedy AR, Klett J, Mulvey RE, O'Hara CT, Weatherstone S (2008). Angew Chem Int Ed 47:8079

26. Armstrong DR, García-Álvarez P, Kennedy AR, Mulvey RE, Parkinson JA (2010). Angew Chem Int Ed 49:3185

27. Fraser RR, Mansour TS (1984). J Org Chem 49:3443

28. Wada A, Yamamoto J, Kanatomo S (1987). Heterocycles 26:585

29. Mosrin M, Boudet N, Knochel P (2008). Org Biomol Chem 6:3237

30. Lin W, Baron O, Knochel P (2006). Org Lett 8:5673

31. Jaric M, Haag BA, Unsinn A, Karaghiosoff K, Knochel P (2010). Angew Chem Int Ed 49:5451

32. Boudet N, Lachs JR, Knochel P (2007). Org Lett 9:5525

33. Mosrin M, Knochel P (2009). Chem Eur J 15:1468

34. Piller FM, Knochel P (2009). Org Lett 11:445

35. Kunz T, Knochel P (2011). Chem Eur J 17:866

36. Tanaka S, Tamba S, Tanaka D, Sugie A, Mori A (2011). J Am Chem Soc 133:16734 
37. Tamba S, Mitsuda S, Tanaka F, Sugie A, Mori A (2012). Organometallics $31: 2263$

38. Verhelst T, Maes J, Liu Z, Sergeyev S, Maes BUW (2011). J Org Chem 76:6670

39. Bresser T, Knochel P (2011). Angew Chem Int Ed 50:1914

40. Hirone N, Sanjiki H, Tanaka R, Hata T, Urabe H (2010). Angew Chem Int Ed 49:7762

41. Wunderlich SH, Bresser T, Dunst C, Monzon G, Knochel P (2010). Synthesis: 2670

42. Rohbogner CJ, Wunderlich SH, Clososki GC, Knochel P (2009). Eur J Org Chem:1781

43. Piller FM, Bresser T, Fischer MKR, Knochel P (2010). J Org Chem 75:4365

44. Wunderlich SH, Kienle M, Knochel P (2009). Angew Chem Int Ed 48:7256

45. Wunderlich SH, Knochel P (2009). Angew Chem Int Ed 48:9717

46. Jeganmohan M, Knochel P (2010). Angew Chem Int Ed 49:8520

47. Metzger A, Bernhardt S, Manolikakes G, Knochel P (2010). Angew Chem Int Ed 49:4665

48. Wittig G, Meyer FJ, Lange G (1951). Justus Liebigs Ann Chem 571:167

49. Tochtermann W (1997). Liebigs Ann/Recueil:I

50. Tochtermann W (1966). Angew Chem Int Ed 5:351

51. Coates GE, Heslop JA (1968). J Chem Soc (A):514

52. Seitz LM, Brown TL (1966). J Am Chem Soc 88:4140

53. Hurd DT (1948). J Org Chem 13:711

54. Weiss E (1993). Angew Chem Int Ed Engl 32:1501

55. Kitagawa K, Inoue A, Shinokubo H, Oshima K (2000). Angew Chem Int Ed 39:2481

56. Inoue A, Kitagawa K, Shinokubo H, Oshima K (2001). J Org Chem 66:4333

57. Xu J, Jain N, Sui Z (2004). Tetrahedron Lett 45:6399

58. Dumouchel S, Mongin F, Trécourt F, Quéguiner G (2003). Tetrahedron Lett 44:2033

59. Dumouchel S, Mongin F, Trécourt F, Quéguiner G (2003). Tetrahedron Lett 44:3877

60. Dumouchel S, Mongin F, Trécourt F, Quéguiner G (2003). Tetrahedron 59:8629

61. Iida T, Wada T, Tomimoto K, Mase T (2001). Tetrahedron Lett 42:4841

62. Catel D, Chevallier F, Mongin F, Gros PC (2012). Eur J Org Chem:53

63. Catel D, Payen O, Chevallier F, Mongin F, Gros PC (2012). Tetrahedron 68:4018

64. Kondo J, Inoue A, Shinokubo H, Oshima K (2001). Angew Chem Int Ed 40:2085

65. Inoue A, Kondo J, Shinokubo H, Oshima K (2002). Chem Eur J 8:1730

66. Thomas GL, Ladlow M, Spring DR (2004). Org Biomol Chem 2:1679

67. Sośnicki JG (2009). Synlett:2508

68. Inoue A, Kitagawa K, Shinokubo H, Oshima K (2000). Tetrahedron 56:9601 
69. Liu M, Kamienski C, Morton M, Fetters LJ (1986). J Macromol Sci, Pure Appl Chem A23:1387

70. Hsieh HL, Wang IW (1986). Macromolecules 19:299

71. Maréchal J-M, Carlotti S, Shcheglova L, Deffieux A (2004). Polymer 45:4641

72. Hsueh M-L, Ko B-T, Athar T, Lin C-C, Wu T-M, Hsu S-F (2006). Organometallics 25:4144

73. Honeyman GW, Kennedy AR, Mulvey RE, Sherrington DC (2004). Organometallics 23:1197

74. Hatano M, Matsumura T, Ishihara K (2005). Org Lett 7:573

75. Sośnicki JG (2005). Tetrahedron Lett 46:4295

76. Sośnicki JG (2007). Tetrahedron 63:11862

77. Sośnicki JG (2006). Tetrahedron Lett 47:6809

78. Sośnicki JG, Struk L (2009). Synlett:1812

79. Fleming FF, Gudipati V, Steward OW (2002). Org Lett 4:659

80. Fleming FF, Gudipati V, Steward OW (2003). Tetrahedron 59:5585

81. Kikuchi M, Niikura S, Chiba N, Terauchi N, Asaoka M (2007). Chem Lett $36: 736$

82. Awad H, Mongin F, Trécourt F, Quéguiner G, Marsais F, Blanco F, Abarca B, Ballesteros R (2004). Tetrahedron Lett 45:6697

83. Bayh O, Awad H, Mongin F, Hoarau C, Trécourt F, Quéguiner G, Marsais F, Blanco F, Abarca B, Ballesteros R (2005). Tetrahedron 61:4779

84. Bayh O, Awad H, Mongin F, Hoarau C, Bischoff L, Trécourt F, Quéguiner G, Marsais F, Blanco F, Abarca B, Ballesteros R (2005). J Org Chem 70:5190

85. Bentabed-Ababsa G, Blanco F, Derdour A, Mongin F, Trécourt F, Quéguiner G, Ballesteros R, Abarca B (2009). J Org Chem 74:163

86. Conway B, Hevia E, Kennedy AR, Mulvey RE (2007). Chem Commun:2864

87. Bellamy E, Bayh O, Hoarau C, Trécourt F, Quéguiner G, Marsais F (2010). Chem Commun 46:7043

88. Andrikopoulos PC, Armstrong DR, Hevia E, Kennedy AR, Mulvey RE, O'Hara CT (2005). Chem Commun:1131

89. Mongin F, Bucher A, Bazureau JP, Bayh O, Awad H, Trécourt F (2005). Tetrahedron Lett 46:7989

90. Hawad H, Bayh O, Hoarau C, Trécourt F, Quéguiner G, Marsais F (2008). Tetrahedron 64:3236

91. Awad H, Mongin F, Trécourt F, Quéguiner G, Marsais F (2004). Tetrahedron Lett $45: 7873$

92. Hatano M, Ishihara K (2008). Synthesis:1647

93. Hatano M, Suzuki S, Ishihara K (2010). Synlett:321

94. Hatano M, Suzuki S, Ishihara K (2006). J Am Chem Soc 128:9998

95. Murakami K, Yorimitsu H, Oshima K (2009). J Org Chem 74:1415

96. Studte C, Breit B (2008). Angew Chem Int Ed 47:5451

97. Hevia E, Chua JZ, García-Álvarez P, Kennedy AR, McCall MD (2010). Proc Nat Acad Sci USA 107:5294 
98. Armstrong DR, Clegg W, García-Álvarez P, McCall MD, Nuttall L, Kennedy AR, Russo L, Hevia E (2011). Chem Eur J 17:4470

99. Armstrong DR, Clegg W, García-Álvarez P, Kennedy AR, McCall MD, Russo L, Hevia E (2011). Chem Eur J 17:8333

100. Forret R, Kennedy AR, Klett J, Mulvey RE, Robertson SD (2009). Organometallics 29:1436

101. Armstrong DR, Kennedy AR, Mulvey RE, Rowlings RB (1999). Angew Chem Int Ed 38:131

102. Hevia E, Gallagher DJ, Kennedy AR, Mulvey RE, O’Hara CT, Talmard C (2004). Chem Commun:2422

103. Armstrong DR, Clegg W, Dale SH, Graham DV, Hevia E, Hogg LM, Honeyman GW, Kennedy AR, Mulvey RE (2007). Chem Commun:598

104. Andrikopoulos PC, Armstrong DR, Graham DV, Hevia E, Kennedy AR, Mulvey RE, O'Hara CT, Talmard C (2005). Angew Chem Int Ed 44:3459

105. Kennedy AR, Mulvey RE, O'Hara CT, Robertson GM, Robertson SD (2011). Angew Chem Int Ed 50:8375

106. Andrews PC, Kennedy AR, Mulvey RE, Raston CL, Roberts BA, Rowlings RB (2000). Angew Chem Int Ed 39:1960

107. Clegg W, Henderson KW, Kennedy AR, Mulvey RE, O'Hara CT, Rowlings RB, Tooke DM (2001). Angew Chem Int Ed 40:3902

108. Andrikopoulos PC, Armstrong DR, Clegg W, Gilfillan CJ, Hevia E, Kennedy AR, Mulvey RE, O'Hara CT, Parkinson JA, Tooke DM (2004). J Am Chem Soc 126:11612

109. García-Álvarez J, Graham DV, Hevia E, Kennedy AR, Mulvey RE (2008). Dalton Trans: 1481

110. Clegg W, Conway B, García-Álvarez P, Kennedy AR, Mulvey RE, Russo L, Sassmannshausen J, Tuttle T (2009). Chem Eur J 15:10702

111. Mulvey RE, Blair VL, Clegg W, Kennedy AR, Klett J, Russo L (2010). Nature Chem 2:588

112. Kennedy AR, Klett J, Mulvey RE, Wright DS (2009). Science 326:706

113. Crosbie E, García-Álvarez P, Kennedy AR, Klett J, Mulvey RE, Robertson SD (2010). Angew Chem Int Ed 49:9388

114. Blair VL, Clegg W, Kennedy AR, Livingstone Z, Russo L, Hevia E (2011). Angew Chem Int Ed 50:9857 